GUTIERREZ, Elena. “Corrupción pública: concepto y mediciones. Hacia el Public compliance como herramienta de prevención de riesgos penales".

Polít. crim. Vol. 13, № 25 (Julio 2018) Art. 3, pp. 104-143.

[http://www.politicacriminal.cl/Vol_13/n_25/Vol13N25A3.pdf]

\title{
Corrupción pública: concepto y mediciones. Hacia el Public compliance como herramienta de prevención de riesgos penales ${ }^{1}$
}

\section{Public corruption: concept and measurements. Towards Public compliance as a criminal risks prevention tool}

\author{
Elena Gutiérrez Pérez \\ Investigadora FPU \\ Área de Derecho Penal de la Universidad de Alicante (España) \\ elena.gutierrez@ua.es
}

\begin{abstract}
RESUMEN: En este trabajo se aborda el estudio de la corrupción pública en España a través de la nueva visión del Public compliance, entendido como la simbiosis entre la ética pública y los elementos desarrollados en los programas de cumplimiento normativo en las empresas como mecanismos que permitan construir una estrategia anticorrupción en las Administraciones públicas. Se parte del concepto difuso de corrupción pública y se toman en consideración los instrumentos que permiten medir la corrupción, enfatizando la contradicción existente cuando se emplean datos objetivos y aquellos relacionados con la percepción en España. El estudio plantea la necesidad de estructurar un Public compliance, tratando de extrapolar elementos e instituciones propias de los programas de cumplimiento en las empresas a las estructuras de las Administraciones públicas y, por último, se plantea la responsabilidad penal de los entes públicos.
\end{abstract}

PALABRAS CLAVE: public compliance, riesgos penales, corrupción pública, mecanismos de prevención y control

ABSTRACT: This paper addresses the study of public corruption in Spain from the new perspective of Public Compliance, as the symbiosis between public ethics and the elements developed in compliance programs in companies as mechanisms to build a Anti-corruption strategy in public administrations. It starts from the diffuse concept of public corruption and takes into consideration the instruments that measure corruption, emphasizing the contradiction existing when using objective data and those related to perception in Spain. The paper suggests structure a Public Compliance, trying to extrapolate elements and institutions of compliance programs in companies to the structures of public administrations and, finally, the criminal responsibility of public entities.

KEYWORDS: public compliance, criminal risks, public corruption, control mechanisms and fraud prevention

\footnotetext{
${ }^{1}$ El presente trabajo se inscribe en el marco de los Proyectos de Investigación "Derechos del condenado y límites derivados de la necesidad de pena. Especial referencia a la delincuencia de género, patrimonial y económica, corrupción, criminalidad organizada y terrorismo" (DER2014-54764-R), financiado por el Ministerio de Economía y Competitividad, cuya investigadora principal es la Prof. Carmen Juanatey Dorado y "La corrupción política y la financiación ilegal de los partidos políticos" (Gre 14-17), financiado por la Universidad de Alicante, cuyo investigador principal es el Prof. Juan Carlos Sandoval Coronado.
} 
Polít. crim. Vol. 13, № 25 (Julio 2018) Art. 3, pp. 104-143.

[http://www.politicacriminal.cl/Vol_13/n_25/Vol13N25A3.pdf]

\title{
A modo de introducción: Una breve nota del concepto (perverso) de corrupción pública
}

\begin{abstract}
"Ya sea que la actividad sea pública, privada o sin fines de lucro, ya sea que uno esté en Nueva York o en Nairobi, uno tenderá a encontrar corrupción cuando alguien tiene un poder monopolístico sobre un bien o un servicio, tiene el poder discrecional de decidir si alguien lo recibirá o no y en qué cantidad, y no está obligado a rendir cuentas. La corrupción es un crimen de cálculo, no un crimen pasional. En verdad, hay santos que resisten todas las tentaciones, y funcionarios honrados que resisten la mayoría de ellas. Pero cuando el tamaño del soborno es considerable y el castigo, en caso de ser atrapado, es pequeño, muchos funcionarios sucumbirán. El combate contra la corrupción, por lo tanto, empieza con mejores sistemas". ${ }^{2}$
\end{abstract}

En efecto, lo expresa muy gráficamente Klitgaard, la corrupción es un crimen de cálculo, no un crimen pasional, y para combatir la corrupción se requiere de "sistemas"3 ¿Pero qué sistemas aplicar para prevenir y detectar la corrupción en el sector público? Ése es el quid de la cuestión. El camino hacia este propósito no es sencillo desde la raíz. El primer aspecto que presenta aristas no es otro que la propia delimitación del objeto de estudio que supone el punto de partida del presente trabajo. Si se pretende atajar la corrupción en la Administración a través de medidas de prevención y control, el primer paso ineludible consiste en trazar los elementos que construyen el concepto de corrupción pública. Y, precisamente, la definición de la corrupción pública no ha sido un aspecto pacífico ${ }^{4}$, muy al contrario, los matices son muy variados. La solución pasa por ofrecer una definición de mínimos o tratar de encontrar una definición rigurosa que aporte más información sobre el fenómeno ${ }^{5}$. La complejidad que supone ofrecer un concepto preciso ha provocado el efecto inverso, esto es, que se evite definirlo, acudiendo a la "socorrida" solución de asimilar la corrupción pública a los tipos penales de corrupción ${ }^{6}$. Esta opción distorsionaría el concepto, ya que equipara la corrupción punible a la corrupción pública.

Desde la perspectiva del Derecho Administrativo, la corrupción pública se ha definido como "una mala administración o un mal gobierno dolosos en el ejercicio de poderes públicos que no busca el interés general, sino el beneficio de una persona física o jurídica"7. Dentro de la propia corrupción pública existe otra tipología subyacente de

\footnotetext{
${ }^{2}$ KLITGAARD, Robert, Controlling Corruption, Berkeley: University of California Press, 1988, p.4.

${ }^{3}$ Para KLITGAARD la corrupción se resume en una ecuación: $C=M+D-A$. La corrupción se generaría, según este autor, como consecuencia de un monopolio de la decisión $(M)$ más discrecionalidad (D) menos rendición de cuentas (Accountability, en inglés). Vid. KLITGAARD, Robert, Controlando la corrupción. Una indagación práctica para el gran problema del fin de siglo, Buenos Aires: Ed. Sudamericana, p. 10 y ss.

${ }^{4}$ NIETO GARCÍA señala que "se habla mucho de corrupción, pero curiosamente no existe un concepto generalmente admitido de lo que pueda significar". Véase, ampliamente sobre la cuestión, NIETO GARCÍA, Alejandro, Corrupción en la España democrática, Barcelona: Ariel, 1997, p. 76.

${ }^{5}$ VILLORIA MENDIETA, Manuel e IZQUIERDO SÁNCHEZ, Agustín, Ética pública y buen gobierno. Regenerando la democracia y luchando contra la corrupción desde el servicio público, Madrid: Tecnos, 2016, p. 238.

${ }^{6}$ Muestra de ello es el caso de la Convención de Naciones Unidas contra la Corrupción de 2003.

7 PONCE SOLÉ, Juli, "La prevención de la corrupción mediante la garantía del derecho a un buen gobierno y a una buena administración en el ámbito local (con referencias al Proyecto de Ley de
} 
GUTIERREZ, Elena. “Corrupción pública: concepto y mediciones. Hacia el Public compliance como herramienta de prevención de riesgos penales".

suma relevancia. Se trata de distinguir en atención al sujeto que promueve o ejecuta la corrupción. Este criterio permite dejar patente la diferencia esencial entre la corrupción política y la administrativa. En la primera, están implicados políticos, sean electos o nombrados por razones de confianza y, la segunda, está conformada por funcionarios o empleados públicos, seleccionados, en principio, por criterios basados en la meritocracia y estabilidad en el puesto. Este concepto abierto de corrupción permite, a su vez, abrir una doble vertiente de la corrupción, al existir una corrupción punible por el Derecho Penal y una corrupción sancionable desde el Derecho Administrativo. Para Nieto García la corrupción pública empieza cuando el poder, que ha sido entregado por el Estado a una persona a título de administrador público, "no se utiliza correctamente al desviarse de su ejercicio, defraudando la confianza de sus mandantes, para obtener un enriquecimiento personal" 8 . La corrupción pública también ha sido definida desde una triple dimensión: como una quiebra de las normas legales -concepción jurídica- o de las normas éticas no escritas -concepción ética-, pero con apoyo social generalizado -concepción sociológica- relativas a cómo se debe ejercer el servicio público, "para proporcionar servicios o beneficios a ciertos grupos o ciudadanos de forma oculta, con ganancia directa o indirecta, en mente" ${ }^{\prime \prime}$.

Las categorías ligadas a la corrupción son tan sutiles que existe una línea divisoria muy fina entre el denominado engrasamiento y el clima de corrupción ${ }^{10}$. En el engrasamiento, el corruptor realiza cualquier tipo de acto para ganarse la confianza del empleado público a cambio de una contraprestación ligada a su cargo o función. En el clima de corrupción la diferencia estriba en que el corruptor no tiene en mente un concreto comportamiento futuro del empleado público, sino que se entrega o se realiza algo sin esperar una contraprestación específica. El ejemplo más ilustrativo del clima de corrupción es aquel en el que se hacen regalos o se conceden ventajas a empleados públicos que tratan de fomentar buenas relaciones personales e incluso su disponibilidad de cara al futuro. El propósito de tales esfuerzos por ganar la simpatía y buena voluntad de empleados públicos y privados se dirige a crear un clima interpersonal que pueda tener efectos positivos en relación con sus decisiones. Se espera en el futuro alguna decisión favorable, algún comportamiento especial del empleado o la obtención de alguna ventaja desleal, pero no se tiene en mente un acto concreto del cargo. ¿Es esto ya corrupción pública?

Los delitos de corrupción pública no aparecen delimitados dentro del Código Penal español ${ }^{11}$, sino que se configuran como aquellos tipos que poseen determinadas notas

transparencia, acceso a la información pública y buen gobierno)", Anuario del Gobierno Local, $\mathrm{n}^{\circ} 1$ (2012), pp. 93-140, p. 100.

${ }^{8}$ NIETO GARCÍA, Alejandro, Corrupción en la España democrática, cit. nota nº, p. 7.

9 KJELLBERG, Francesco, "Corruption as an analytical problem: some notes on research in Public Corruption”, Indian Journal of Administrative Sciencie, n³ (1992), pp. 195-221, p. 216.

10 Sobre esta distinción, se sigue lo apuntado por BLANCO CORDERO, Isidoro, "Hospitalidad e invitaciones a empleados públicos y privados: riesgo penal y cumplimiento normativo empresarial", en JAREÑO LEAL, Ángeles, y DOVAL PAIS, Antonio, Corrupción pública, prueba y delito: Cuestiones de libertad e intimidad, Cizur Menor: Aranzadi, 2015, pp. 67-86, p. 72.

${ }^{11} \mathrm{Si}$ bien se contemplan los delitos de corrupción en los negocios y, tras la Ley Orgánica 1/2015, de 30 de marzo, dentro de éstos, los delitos de corrupción en las transacciones económicas internacionales del art. 286 ter. 
Polít. crim. Vol. 13, № 25 (Julio 2018) Art. 3, pp. 104-143.

[http://www.politicacriminal.cl/Vol_13/n_25/Vol13N25A3.pdf]

criminológicas propias de la corrupción ${ }^{12}$. La flexibilidad con la que se hace referencia a los "delitos de corrupción pública" ha propiciado un vaciamiento de su concepto, especialmente incentivado por el uso que se hace en los medios de comunicación que, en muchas ocasiones, han pervertido su significado, arrastrando hacia sus confines prácticamente a todo delito relacionado con la figura de políticos ${ }^{13}$. Parece que todo puede ser corrupción. En efecto, como señalaba Saussure, el punto de vista es quien crea el objeto ${ }^{14} \mathrm{y}$, este presupuesto, en el terreno de la corrupción, opera en todo su esplendor. Para De la Mata Barranco la conducta corrupta "habrá que analizarla a través del delito que sea el que trate de atajar la misma y no otro tipo de menoscabo a un interés necesitado de tutela". Pese a que ello nos remite a los delitos contra la Administración Pública, insiste en que determinados delitos como el delito de malversación de caudales públicos o los fraudes no conformarían estrictamente el elenco de delitos de corrupción porque se adolecería del elemento corruptor ${ }^{15}$. Este autor estima que la corrupción pública, en su versión más estricta, estaría más íntimamente ligada al delito de cohecho y al de tráfico de influencias, que "son los que reflejan ese co-hacer de dos con finalidades no convergentes, pero sí encontradas" 16.

No obstante, esta concepción tan restringida de los delitos considerados de corrupción pública me parece demasiado rigurosa con la estructura clásica que contempla la existencia de un corruptor y un corrupto. El abuso de poder como desvío de las funciones públicas con fines privados debe ser la nota preponderante, máxime cuando la corrupción contemporánea ha difuminado la frontera entre lo público y lo privado, por el crecimiento de la Administración pública y la diversificación del proceso de toma de decisiones en el aparato público ${ }^{17}$. En este sentido, Doval Pais y Juanatey Dorado equiparan como delitos de corrupción pública, con algunos matices, la categoría de delitos contra la Administración pública, ya que son los que esencialmente implican «la utilización de bienes o servicios públicos para el ilícito favorecimiento de intereses particulares», si bien admitiendo que esta asimilación puede dar lugar tanto a sobreinclusiones como a infrainclusiones ${ }^{18}$. De forma amplia se ha estimado que la

\footnotetext{
12 Sobre la raíz criminológica del concepto, véase DOVAL PAIS, Antonio, "Delitos de corrupción pública: indultos y condenas", en: JAREÑO LEAL, Ángeles, Corrupción pública: Cuestiones de política criminal (I), Madrid: Iustel, pp. 41-62, p. 44.

13 Denuncia esta situación, DE LA MATA BARRANCO, Norberto, "La lucha contra la corrupción política”, Revista Electrónica de Ciencia Penal y Criminología, n¹8 (2016), pp. 1-25, p. 7.

${ }^{14}$ Vid. VILLORIA e IZQUIERDO, Ética pública y buen gobierno..., cit. nota ${ }^{\circ} 5$, p. 237.

15 Añade el autor que pese a ser abusos de poder o abusos de situaciones de privilegio, "no implican en todos los casos (o no tienen por qué hacerlo) desvío del ejercicio de la función pública (o perjuicio a ésta), ni enriquecimiento económico, ni, en definitiva, compraventa del poder público". Vid. DE LA MATA BARRANCO, "La lucha contra la corrupción política", cit. nota nº13, p. 7.

${ }^{16}$ Más exhaustivamente, DE LA MATA BARRANCO, Norberto, La respuesta penal a la corrupción pública: el tratamiento penal de los particulares que contribuyen a ella, Granada: Comares, pp. 3 y ss.

17 LUZÓN PEÑA insiste en los perfiles que asisten hoy a la corrupción contemporánea frente a la corrupción histórica o tradicional señalando que "lo más característico de la moderna corrupción es que las figuras delictivas ligadas a la corrupción presentan cada vez más importantes vínculos con otras formas de la delincuencia como el fraude fiscal a gran escala o el blanqueo, lo que impide abordar el fenómeno de la corrupción como una cuestión exclusivamente local". Véase, LUZÓN PEÑA, Alejandro, “Instrumentos para la investigación de la corrupción”, Cuadernos penales José María Lizón, no 11 (2015), pp. 235-254, p. 238.

18 Esta asimilación abarca algunos delitos que poco o nada se relacionan con la corrupción (delitos de abandono de destino y de omisión del deber de perseguir delitos, los de desobediencia y denegación de auxilio) y, como reverso, omite otros que no perteneciendo a la categoría de delitos contra la Administración pública, sin embargo, son modalidades frecuentes de conductas corruptas (delitos de falsedades, delitos contra la Hacienda Pública, blanqueo de capitales, entre otros). Vid. DOVAL PAIS,
} 
GUTIERREZ, Elena. “Corrupción pública: concepto y mediciones. Hacia el Public compliance como herramienta de prevención de riesgos penales".

corrupción pública se equipara al "abuso de posición por un servidor público, con un beneficio extraposicional directo o indirecto (para el corrupto o los grupos de que forma parte éste), con incumplimiento de normas jurídicas que regulan el comportamiento de los servidores públicos" $"$.

Se ha de reconocer que pocos conceptos se emplean con una riqueza semántica tan amplia como el concepto de corrupción tanto es así que "corrupción" puede ser casi todo y, al mismo tiempo, casi nada: ¿Es corrupción la inactividad, la inacción, ante un comportamiento corrupto? Ahondando en esta cuestión, Della Porta y Vanucci definen la corrupción como "aquellas acciones u omisiones que tienen que ver con el uso abusivo de los recursos públicos para beneficios privados, a través de transacciones clandestinas que implican la violación de algún modelo de comportamiento" 20 . En toda corrupción hay un intento de obtener un beneficio, sea económico o no, se consiga o no finalmente. En cualquier caso, es el abuso de posición el elemento relevante, a mi parecer, más allá de que exista una oferta de beneficio extraposicional ${ }^{21}$.

Una vez efectuadas estas precisiones, el propósito de las líneas siguientes es ahondar en el estudio de la corrupción pública en España a través de la nueva visión del Public compliance, entendido como la simbiosis entre la ética pública y los elementos desarrollados en los programas de cumplimiento normativo en las empresas como mecanismos que permitan construir una estrategia anticorrupción en las Administraciones públicas ${ }^{22}$. Para ello, se parte de los instrumentos que permiten medir la corrupción, enfatizando la contradicción existente cuando se emplean datos objetivos y aquellos relacionados con la percepción en España. A continuación, se plantea la necesidad de estructurar un Public compliance, tomando como premisa los principales datos cuantitativos y cualitativos que hasta el momento se disponen del fenómeno de la corrupción pública. Para lograr este cometido, se tratan de extrapolar elementos e instituciones propias de los programas de cumplimiento en las empresas a las estructuras de las Administraciones públicas, replanteando las figuras que ya existen en estas últimas y, por último, se esbozan algunas cuestiones en torno a la responsabilidad penal en que pueden incurrir los entes públicos en el Código penal español.

\section{La medición de la corrupción pública en España. La dualidad entre percepción y datos objetivos}

Antonio, y JUANATEY DORADO, Carmen, "Particularidades de los indultos por delitos de corrupción pública", en: MAQUEDA ABREU, María Luisa, MARTÍN LORENZO, María y VENTURAL PÜSCHEL, Arturo (Coords.), Derecho Penal para un estado social y democrático de derecho. Estudios penales en homenaje al profesor Emilio Octavio de Toledo y Ubieto, Madrid: Servicio de Publicaciones de la Facultad de Derecho de la Universidad Complutense de Madrid, 2016, pp. 95-110, pp. 96 y 97.

${ }^{19} \mathrm{El}$ beneficio extraposicional se entiende como aquel beneficio que no está previsto entre los beneficios legítimos que corresponden a un determinado cargo o posición. Véase, GARZÓN VALDÉS, Ernesto, “Acerca del concepto de corrupción”, en: LAPORTA SAN MIGUEL, Francisco, y ÁLVAREZ MEDINA, Silvina, La corrupción política, Madrid: Alianza Editorial, 1997, pp. 39-70, pp. 43 y ss.

20 DELLA PORTA, Donatella, y VANUCCI, Alberto, "Los recursos de la corrupción: algunas reflexiones sobre el caso italiano", Zona Abierta, n98/99 (2002), pp. 85-118, p. 86.

${ }^{21}$ De esta opinión, VILLORIA e IZQUIERDO, Ética pública y buen gobierno..., cit. nota nº5, p. 245.

${ }^{22}$ La primera referencia en materia penal en España, NIETO MARTÍN, Adán, "De la ética pública al public compliance: sobre la prevención de la corrupción en las administraciones públicas", en: EL MISMO y MAROTO CALATAYUD, Manuel, (Dirs.), Public Compliance. Prevención de la corrupción en administraciones públicas y partidos políticos, Cuenca: Ediciones Universidad Castilla La Mancha, 2014, pp. 17-42, p. 17. 
Cuando se aborda un problema como el fenómeno de la corrupción pública, el principal obstáculo se encuentra en su cuantificación. Su análisis más habitual se lleva a cabo a través de métodos que pueden ser objetivos ${ }^{23}$ y subjetivos $^{24}$. En primer término, se puede realizar desde un prisma considerado objetivo, cuantificando las denuncias de corrupción, las investigaciones abiertas por el Ministerio Público o los Jueces de Instrucción, así como las sentencias condenatorias. En segundo término, la vertiente subjetiva engloba indicadores basados en la experiencia y percepciones, bien a través de encuestas de percepción de corrupción a inversores nacionales y extranjeros, a expertos y a la ciudadanía en general o, por último, mediante encuestas de victimización, en las que se pregunta a los ciudadanos por sus experiencias directas con la corrupción principalmente sobornos o extorsiones para el acceso a la prestación de servicios públicos-.

Los escándalos de corrupción producidos en las Administraciones públicas han inundado en los últimos años la actualidad de los medios de comunicación en España. Tanto es así que la preocupación por la corrupción por parte de los ciudadanos ha ido creciendo exponencialmente con el paso del tiempo. El barómetro del CIS, de noviembre de 2016, vuelve a situar la corrupción como el segundo mayor problema de España $^{25}$. La "sensación térmica" de los ciudadanos sobre la corrupción es muy elevada, de facto, para hallar una preocupación tan acusada por la corrupción hay que remontarse, desde que existen datos del CIS, al año 1995, en el que España finiquitaba una crisis iniciada en 1993 y que, precisamente, tenía como notas predominantes una recesión económica y un alto porcentaje de paro $^{26}$. No obstante, conviene puntualizar que este alud de casos de corrupción procede, en su mayoría, de una época ligada a la burbuja inmobiliaria y la bonanza económica, especialmente, en el último trimestre de 2007. Se estaría ante un "retraso en los efectos" o lag times que abriría el interrogante de si esa sensación de mayor corrupción es engañosa, pues los casos mediáticos generan la impresión de que la corrupción es mayor que cuando no se perseguía. Se incrementa así la percepción de corrupción por parte de los ciudadanos cuando realmente podría estar reduciéndose. Por ello, es esencial trazar una distinción entre la "corrupción real" y la que marcan los índices de la percepción de la corrupción.

\footnotetext{
${ }^{23}$ El Programa de las Naciones Unidas para el Desarrollo define los indicadores objetivos como aquellos construidos a partir de hechos no controvertidos. Guía del usuario para medir la corrupción, Oslo, Noruega: Programa de Desarrollo de Naciones Unidas PNUD, 2009, p. 9.

${ }^{24}$ Véase, con mayor detalle, SOLIMANO, Andrés, "La corrupción: motivaciones individuales, fallas del Estado y desarrollo", en: EL MISMO, TANZI, Vito, y DEL SOLAR, Felipe, Las termitas del Estado, Chile: Fondo de cultura económica-CiGLOB, 2008, pp. 57-88. Aunque actualmente la medición se ha convertido en un tema de relevante investigación, por lo que se pueden apuntar hasta 15 instrumentos de medición, algunos de ellos bastante sofisticados. Véase, UNDP and Global Integrity: A user's Guide to Measuring Coruption, Oslo, UNDP Oslo Governance Center. www.lulu.com/content/2523351 (Último acceso: 05/12/2016)

${ }^{25}$ En el Barómetro del Centro de Investigaciones Sociológicas, de noviembre de 2016, se recoge la percepción de los ciudadanos acerca de los tres principales problemas que existen actualmente en España. http://www.cis.es/cis/export/sites/default/Archivos/Indicadores/documentos_html/TresProblemas.html (Último acceso: 07/12/2016).

${ }^{26}$ Así lo pone de manifiesto TARÍN, Carolina, "La medición de la corrupción en España: Los datos objetivos", en: VILLORIA MENDIETA, Manuel, GIMENO FELIÚ, José María, y TEJEDOR BIELSA, Julio, La corrupción en España. Ámbitos, causas y remedios jurídicos, Barcelona: Atelier, 2016, pp. 6782, p. 67.
} 
GUTIERREZ, Elena. “Corrupción pública: concepto y mediciones. Hacia el Public compliance como herramienta de prevención de riesgos penales".

En la Guía del usuario para medir la corrupción de la ONU se hace referencia, entre otros, a dos tipos de indicadores para medir la corrupción: los basados en una única fuente de información y los compuestos. Estos últimos, también denominados proxy, tienen un carácter indirecto, pues ayudan a medir la corrupción a través de la agregación de diferentes indicadores. De esta manera, la corrupción, como fenómeno complejo, se analiza teniendo en cuenta diversos signos o señales característicos, ya que no existe un único indicador que contenga suficiente información para efectuar una visión de conjunto. En suma, la combinación de los indicadores objetivos y subjetivos permite aproximarse criminológicamente, de forma más fiable, al estudio de la corrupción ${ }^{27}$.

\subsection{Medición objetiva}

La medición de la corrupción empleando datos objetivos deviene en una tarea sumamente ardua en España, ya no sólo por la complejidad del fenómeno, sino precisamente por la inexistencia de datos públicos que permitan realizar un estudio preventivo sólido ${ }^{28}$. A ello se adiciona el propósito difuso de las mediciones objetivas, en las que no se conoce si lo que se mide realmente es la calidad del sistema judicial, por el número de condenas que finalmente se han producido, o la eficacia policial en sus investigaciones. Un país en el que la corrupción sea muy acusada puede no tener en las estadísticas judiciales un correlato sencillamente porque existe impunidad y, en su reverso, un país con una corrupción más controlada puede tener mayor número de condenas y causas abiertas porque la corrupción es más perseguida por la policía y el sistema judicial ${ }^{29}$.

Los principales indicadores objetivos sirven como instrumento para medir la corrupción penalmente punible -datos del Consejo General del Poder Judicial, Ministerio del Interior, Fiscalía General del Estado o Registro Central de Penados-. Sin embargo, una fuente tan valiosa como las estadísticas sobre los procesos de corrupción acaecidos sólo existe desde principios del año $2017^{30}$, tras la publicación del repositorio del Consejo General del Poder Judicial de datos sobre procesos de corrupción ${ }^{31}$. Este repositorio presenta estadísticas ordenadas por trimestres de 2015 y 2016, por Comunidades Autónomas y desglosadas en función del órgano jurisdiccional encargado del enjuiciamiento. Se contabilizan los procesos penales por delitos relacionados con la corrupción pública ${ }^{32}$, abarcando tanto a los que tengan un auto de procesamiento o de

\footnotetext{
${ }^{27}$ En este sentido, TARÍN, "La medición de la corrupción...", cit. nota n 26, p. 69.

${ }^{28}$ Ya lo advirtieron en su estudio de 2012 los profesores VILLORIA MENDIETA, Manuel, y JIMÉNEZ SÁNCHEZ, Fernando, “¿Cuánta corrupción hay en España? Los problemas metodológicos de la medición de la corrupción (2004-2011)", en Revista de Estudios Políticos, nº156 (2012), pp. 13-47, y el informe de la Fundación ¿Hay Derecho? "Corrupción institucional y controles administrativos preventivos" (2015). Ante la carencia de datos objetivos, se han intensificado las acciones ciudadanas que buscan la transparencia como mecanismo para detectar irregularidades en las entidades locales. Un ejemplo de ello son los Observatorios municipales ciudadanos. Puede consultarse mayor información sobre esta institución en el siguiente enlace: http://ocmunicipal.net/

${ }^{29}$ Destacadamente, VILLORIA e IZQUIERDO, Ética pública y buen gobierno..., cit. nota n ${ }^{\circ}$ 5, p. 249.

${ }^{30}$ El CGPJ hizo público el repositorio de datos de procesos por corrupción el 12 de enero de 2017. Puede consultarse en el Portal de Transparencia del CGPJ en el siguiente enlace: http://www.poderjudicial.es/cgpj/es/Temas/Transparencia/Repositorio-de-datos-sobre-procesos-porcorrupcion/Informacion--general/ (Último acceso: 18/01/2017).

${ }^{31}$ Este repositorio es fruto del convenio de colaboración que firmó con Transparencia Internacional. Una relación pormenorizada sólo existía con anterioridad en materia de violencia de género.

${ }^{32}$ A estos efectos el repositorio considera a los siguientes delitos integrados dentro de la categoría corrupción pública: i. Ordenación del territorio, urbanismo y patrimonio histórico. Arts. 320 y 322 CP; ii.
} 
Polít. crim. Vol. 13, № 25 (Julio 2018) Art. 3, pp. 104-143.

[http://www.politicacriminal.cl/Vol_13/n_25/Vol13N25A3.pdf]

apertura de juicio oral como a los condenados por sentencia firme. Los datos del repositorio establecen que, entre el 1 de julio de 2015 y el 30 de septiembre de 2016, los Juzgados y Tribunales españoles dictaron auto de apertura de juicio oral o de procesamiento por delitos relacionados con la corrupción contra 1.378 personas, de las cuales 399 han sido condenadas en sentencia firme. Los delitos más cometidos se concentran en los tipos de prevaricación administrativa, prevaricación urbanística (delitos contra la ordenación del territorio, urbanismo, medio ambiente y patrimonio histórico) y malversación. No obstante, el repositorio no aporta, a mi juicio, una estadística pormenorizada o profunda que entre en el detalle del tipo de delito cometido y las características del condenado (funcionario, político o contratado laboral) que lo ha perpetrado, así como el nivel de la administración y el ámbito de actuación en el que se produce. Estos datos permiten distinguir cuantitativa y cualitativamente la corrupción política de la administrativa e incluso de lo que se puede catalogar como «casos aislados». Por el contrario, registra datos más generales: el sexo de los acusados o procesados, así como su nacionalidad ${ }^{33}$. De las 99 sentencias dictadas en procedimientos por delitos de corrupción en los cinco trimestres estudiados, 72 fueron total o parcialmente condenatorias, representando el 72,7 por ciento del total ${ }^{34}$.

La Fiscalía General del Estado cuenta con datos en sus memorias agrupados por delitos, permitiendo individualizar aquellos que podrían corresponderse típicamente con la corrupción. El déficit de los datos aportados por la FGE, de nuevo, es la no identificación del sujeto, en el sentido de si se trata de un funcionario o cargo político, por lo que no permite un análisis de raíz. Si bien tienen el aspecto positivo de facilitar el dato del lugar donde se ha producido la condena, por lo que puede ayudar a componer un mapa de la corrupción, considerando las provincias en las que existen mayores cotas de corrupción pública. Asimismo, el Registro Central de Penados, disponible desde 2007, ofrece el número de condenados por sentencia firme cada año por tipo de delito. El problema es que este Registro no permite efectuar una fotografía de conjunto, ya que teniendo en consideración la lentitud de las causas relacionadas con la corrupción (una sentencia firme puede dilatarse hasta 9 ó 10 años, si se cuentan los tiempos de duración de los procesos de primera instancia, en apelación y ante el Tribunal Supremo), el dato de los condenados por corrupción y año no es indicativo o real ${ }^{35}$.

Por último, los datos del INE en relación con el Registro Central de Penados arrojan que las actuaciones corruptas no terminan de trasladarse a las estadísticas de condenas. Una muestra se puede apreciar en que únicamente fueron condenados por tráfico de

Prevaricación de funcionarios públicos. Arts. 404, 405 y $408 \mathrm{CP}$; iii. Infidelidad en la custodia de documentos y violación de secretos. Arts. 413, 414, 415, 416, 417 y 418 CP; Cohecho. Arts. 419, 420, 421 y 422 CP; iv. Tráfico de influencias. Arts. 428, 429 y 430 CP; Malversación. Arts. 432, 433, 434 y $435 \mathrm{CP}$; v. Fraudes y exacciones ilegales. Arts. 436, 437 y 438 CP; vi. Negociaciones y actividades prohibidas a los funcionarios públicos y de los abusos en el ejercicio de su función. Arts. 439, 441, 442 y $443 \mathrm{CP}$; vii. Corrupción en las transacciones comerciales internacionales. Arts. $286.3^{\circ}$ y $4^{\circ} \mathrm{CP}$.

${ }^{33}$ Las estadísticas contabilizan que 1.060 eran hombres -el 77 por ciento- y 318 mujeres. La base de datos -que permite consultas de manera global para toda España o de manera detallada en el ámbito de cada Comunidad Autónoma- ofrece también información sobre la nacionalidad de los implicados: 1.174 eran españoles, 34 de Estados miembros de la Unión Europea y 170 extracomunitarios.

${ }^{34}$ La información ofrecida detalla, dentro de las sentencias condenatorias, las que lo han sido con y sin conformidad, así como las parcialmente condenatorias (tanto porque no se haya condenado por todos los delitos por los que se acusaba o porque no se haya condenado a la totalidad de los acusados).

${ }^{35}$ Destaca esta falta de correlación entre estadísticas y realidad social, DE LA MATA BARRANCO, "La lucha contra la corrupción política", cit. nota $\mathrm{n}^{\circ} 13$, p. 23. 
GUTIERREZ, Elena. “Corrupción pública: concepto y mediciones. Hacia el Public compliance como herramienta de prevención de riesgos penales".

influencias cuatro personas en 2014, mientras que en 2013 tan sólo una ${ }^{36}$. Jareño Leal apunta, entre otros, motivos explicativos de la escasa cifra de condenas penales por los delitos de prevaricación, cohecho, tráfico de influencias, fraudes y negociaciones prohibidas: el sobreseimiento de las causas que se inician por mera animadversión política, las dificultades probatorias insalvables en una materia tan compleja como la contratación pública o la absolución penal y el desvío a la sanción administrativa ${ }^{37}$.

En suma, pese a que en los últimos tiempos se ha tratado de fomentar la transparencia y perseguir la corrupción, la mayoría de los datos con los que se puede cuantificar la corrupción pública en España proceden de su medición subjetiva, a través de la percepción de los ciudadanos.

\subsection{Medición subjetiva}

La carencia de datos objetivos conduce al obligado recurso a los índices de percepción de la corrupción. Estos índices tienen una primera deficiencia de contenido, al quedar el propio concepto de corrupción a la libre configuración del encuestado y, por tanto, su validez es cuestionable desde un punto de vista de la realidad del fenómeno ${ }^{38}$. El índice de Transparencia Internacional (Corruption Perceptions Index, CPI), compuesto por encuestas realizadas a expertos y empresarios ${ }^{39}$, es uno de los instrumentos más empleados en el contexto internacional para medir la corrupción. Pese a su indudable utilidad, se aduce como crítica que las puntuaciones que se otorgan a los diferentes países no miden la corrupción en sí, sino que simplemente muestran las opiniones sobre su extensión en los diferentes países ${ }^{40}$. Esta tipología de índices genera el problema de simplificar en exceso la corrupción a un "único número", esto es, se antoja complicado y bajo el riesgo de obtener un resultado sesgado aglutinar en una única cifra qué está sucediendo en un país en torno a un fenómeno poliédrico como es la corrupción. Precisamente, España, de todos los países de la Unión Europea, en tan sólo tres años es el que ha padecido cambios más bruscos en la percepción de la corrupción hasta considerarla como uno de los tres problemas más acuciantes ${ }^{41}$. Una de las fuentes más mencionadas a nivel nacional, los barómetros del CIS sobre corrupción permiten estimar la relevancia de esta materia para los ciudadanos, pero no la evolución real de la corrupción.

En el primer estudio sobre corrupción publicado por la Comisión Europea en $2014^{42}$, en el que se agrupaban dos encuestas que evaluaban la experiencia y percepción de la

\footnotetext{
${ }^{36}$ Datos obtenidos en fecha 29 de mayo de 2016 del INE en relación con los datos del Registro Central de Penados.

37 JAREÑO LEAL, Ángeles, "La corrupción en la contratación pública", en: LA MISMA, Corrupción pública: Cuestiones de política criminal (I), Madrid: Iustel, 2014, pp. 149-158, pp. 150 y ss.

${ }^{38}$ Así lo ponen de manifiesto VILLORIA MENDIETA e IZQUIERDO SÁNCHEZ, Ética pública y buen gobierno..., cit. nota $\mathrm{n}^{\circ} 5$, p. 257.

39 Para conocer de forma detallada la metodología utilizada por el CPI, consúltese www.transparency.org/cpinota

${ }^{40}$ Sobre las críticas a la medición subjetiva por expertos, VILLORIA e IZQUIERDO, Ética pública y buen gobierno..., cit. nota n 5 , p. 253.

${ }^{41}$ Los datos del Eurobarómetro de 2013 muestran que España es el país en el que los encuestados perciben que ha habido un mayor incremento de la corrupción (77 por ciento). Ello explica, también, que España en el indicador de Transparencia Internacional, en el año 2004, se encontrara en la posición 22, mientras que diez años más tarde cayó al puesto 37 de 175 países.

${ }^{42}$ EU Anti-corruption report, COM (2014), de 3 de febrero 2014.
} 
Polít. crim. Vol. 13, № 25 (Julio 2018) Art. 3, pp. 104-143.

[http://www.politicacriminal.cl/Vol_13/n_25/Vol13N25A3.pdf]

corrupción entre ciudadanos y empresas europeas, España mostraba una percepción peculiar de la corrupción pudiendo ser calificada de dual con respecto a los países homólogos ${ }^{43}$. Los datos de la dualidad en la percepción son abrumadores, pues más de un 95 por ciento de los españoles declararon que la corrupción es un problema muy extendido en el país, mientras que la media europea se sitúa en torno al 76 por ciento. Por el contrario, la experiencia directa a la que se hacía alusión con anterioridad no se corresponde con el alto nivel de percepción: tan sólo el 2 por ciento (por debajo de la media europea que se sitúa en el 4 por ciento) declaró haber tenido que pagar algún soborno para obtener un servicio público. En este sentido, España se encuentra a niveles tales como los de Suecia y Dinamarca. Pese a ello, el 63 por ciento de los ciudadanos españoles estima que la corrupción les afecta en su vida cotidiana y sólo el 10 por ciento considera que los esfuerzos del Gobierno para combatirla son eficaces.

Los datos del último Eurobarómetro (2013) reafirman lo aquí avanzado. Ante la pregunta de si "conoce usted a alguien que acepte sobornos", la media en la Unión Europea es del 12 por ciento y en España los datos son aceptables con un 11 por ciento de respuestas afirmativas. Resulta llamativo que, en otros países, como Holanda, Suecia y Francia, los porcentajes sean más altos $(15,18,16$ por ciento respectivamente). Ante la pregunta de si "le han pedido a usted un soborno en los últimos 12 meses", la media europea de respuestas afirmativas es de 4 por ciento y en España el dato es del 2 por ciento, con áreas como la sanidad o la policía inmaculadas, ya que ninguno de los encuestados afirmó haber pagado un soborno en estas materias sensibles. Y, finalmente, ante la pregunta de "si ha sido usted testigo o le han pedido un soborno en los últimos 12 meses" la media europea es de 8 por ciento, lo que coincide con las respuestas afirmativas en España.

Conviene resaltar que el concepto de corrupción testado por el Eurobarómetro es muy restringido, tanto que equipara la experiencia de corrupción al mero soborno. De ahí que no sea tan alarmante que en España la diferencia entre la experiencia personal de corrupción, medida por las tasas de victimización (haber tenido que pagar un soborno) y las percepciones sea más elevada que en el resto de países ${ }^{44}$. Si la experiencia personal fuera el índice clave en la corrupción, sin duda, España estaría en una posición bien ventajosa, pues se encontraría en los niveles cercanos a Alemania y Holanda, pero se trataría de una conclusión engañosa ${ }^{45}$. La corrupción percibida no se refiere únicamente a los sobornos, sino "a una forma de hacer política basada en la constante intromisión de los intereses particulares en la toma de decisiones políticas y viceversa, con efectos muy perversos para el bienestar colectivo" 46 .

Llegados a este punto, se trata de indagar en el porqué de esta disociación entre el alto grado de percepción social de la corrupción en España y los datos que niegan la corrupción sistémica en la prestación de servicios públicos. Una de las principales

\footnotetext{
${ }^{43}$ Sobre este informe y otros datos relacionados con la corrupción pública en España, véase el informe "Corrupción y calidad democrática" del Círculo de Economía de Barcelona (2015), p. 9. Disponible en: https://drive.google.com/file/d/0B_6aT2v-iXNHMVA1M2lvbTlnalU/view (Último acceso: 09/12/2016).

${ }^{44} \mathrm{Si}$ se contrastan estos datos con los de Hungría, Polonia, Rumanía o Italia se puede comprobar que los datos de victimización son superiores en todos estos países, pero la percepción ciudadana es más baja que en España.

${ }^{45}$ Así lo ponen de relieve VILLORIA e IZQUIERDO, Ética pública y buen gobierno..., cit. nota nº, p. 257.

${ }^{46}$ VILLORIA e IZQUIERDO, Ética pública y buen gobierno ..., cit. nota n5, p. 257.
} 
GUTIERREZ, Elena. “Corrupción pública: concepto y mediciones. Hacia el Public compliance como herramienta de prevención de riesgos penales".

causas que pueden atribuirse a la percepción social es la cobertura mediática de la corrupción en los medios de comunicación ${ }^{47}$. Sólo entre 2008 y 2010 se calcula que casi el 50 por ciento de las noticias en la prensa nacional y regional abordaban la corrupción, la crisis económica y las tensiones partidistas ${ }^{48}$. Y ello acaba encontrando una correlación: cuando más ávido lector de prensa sea el ciudadano, mayor es la precepción de corrupción en el nivel político ${ }^{49}$. Otro de los aspectos que pueden afectar a la percepción social de la corrupción tiene su foco en el devenir económico del país. Así pues, con la crisis económica, los ciudadanos tienden a pensar que el gobierno es más corrupto. Este hecho se puede constatar en los diferentes barómetros del CIS, en los que existe una correlación entre la percepción del rendimiento económico y la consideración de la corrupción como uno de los tres problemas más acuciantes de España. Pero esta correlación se incrementa cuando el porcentaje de personas que creen que la situación económica del país es «mala o muy mala» supera el 50 por ciento. También existe una poderosa conexión entre las percepciones de que la economía "va mal o muy mal" y la percepción de los políticos como uno de los tres más importantes problemas del país.

En lo que respecta a la contratación pública, los datos del Eurobarómetro 374 (2014), que aborda las actitudes de las empresas ante la corrupción en la Unión Europea, son muy ilustrativos. Con carácter general, las empresas del área de la construcción son las que tienen percepciones más altas sobre corrupción en toda Europa, pero especialmente en España, es la construcción de infraestructura y la gestión de los residuos los espacios de corrupción que acaparan el mayor porcentaje (el 97 por ciento frente al 75 por ciento de la media europea). La corrupción, para el 54 por ciento de las empresas españolas, es un problema al hacer negocios (frente al 43 por ciento de la media europea), el patronazgo lo es para el 46 por ciento (frente al 41 por ciento de la media europea). La conclusión que puede extraerse es que España se encuentra en el podio, de nuevo en medición subjetiva, en Europa, en la creencia por parte de sus empresas de la existencia de corrupción en la contratación: 83 por ciento a nivel nacional y 90 por ciento a nivel regional y local (cifrándose la media europea en un 56 y 60 por ciento, respectivamente). El 93 por ciento de las empresas españolas estima que la corrupción y el favoritismo daña los negocios (frente al 73 por ciento en la media europea); y el 78 por ciento considera que los sobornos y las conexiones son la forma más sencilla de obtener servicios públicos (frente al 69 por ciento de la media europea).

Especialmente reveladora del clima de corrupción existente para poder ascender en la escala social es una encuesta realizada en 2010, en la que se preguntó cuál era el factor más relevante para llegar a ser rico en la sociedad española ${ }^{50}$. Los datos son abrumadores: más del 56 por ciento apuntó "tener buenos contactos y cultivarlos", casi el 20 por ciento respondió "tener buena suerte" y únicamente el 18 por ciento seleccionó "tener buenas ideas y esforzarse en aplicarlas". Estos datos explican que lo que se percibe como normal en el ámbito de la política es el dogma "el sistema funciona asís” y,

\footnotetext{
${ }^{47}$ El aumento de la preocupación por la corrupción de los ciudadanos a través de los barómetros del CIS coincide con la aparición de casos mediáticos (caso Noós, los ERE en Andalucía o el caso Gürtel).

${ }^{48}$ Poniéndolo de manifiesto, VILLORIA e IZQUIERDO, Ética pública y buen gobierno..., cit. nota $\mathrm{n}^{\circ} 5$, p. 259.

49 DE LANCER, Patria, y VILLORIA MENDIETA, Manuel, "Understanding and addressing citizens perceptions of corruption: the case of Spain", en International Review of Public Administration, n¹9 (2013), pp. 23-43.

${ }^{50}$ Sobre esta encuesta, véase, JIMÉNEZ SÁNCHEZ, Fernando, y CARBONA, Vicente, “«Esto funciona así» Anatomía de la corrupción en España”, Lletras Llibres, n¹25 (2012), pp. 23-43.
} 
Polít. crim. Vol. 13, № 25 (Julio 2018) Art. 3, pp. 104-143.

[http://www.politicacriminal.cl/Vol_13/n_25/Vol13N25A3.pdf]

por ello, los actores que en él participan se dedican a invertir tiempo en el cultivo de esas redes clientelares sociales. Esta percepción es cultural y educativa. Ello conecta con la idea de Cox sobre la importancia de la cultura organizativa: la corrupción es conducta aprendida. Sobrevive porque dentro de la organización se convierte en conocimiento tácito de cómo hacer las cosas y tener éxito, con ello, se justifica y se hace atractiva para sus miembros ${ }^{51}$.

En definitiva, los índices de percepción de la corrupción pueden ser relevantes como "termómetro" de la opinión de la ciudadanía en un país, pero no pueden alzarse como parámetro decisivo. Para una comprensión unitaria del problema deben recurrirse a las mediciones objetivas para detectar si existe o no una correlación.

\title{
1.3 La singular concepción de la corrupción sistémica
}

La percepción de la corrupción de la sociedad española, como se ha explicitado supra, es muy elevada, sin embargo, conviene interrogarse acerca de si esta alta percepción subjetiva es indicadora de lo que los expertos denominan corrupción sistémica. Bajo el paraguas de la corrupción sistémica, en opinión de Villoria Mendieta, se engloba las siguientes situaciones:

\begin{abstract}
"Si cuando usted sale a la calle hay bastantes posibilidades de que cualquier policía le pare y le pida un soborno, si la aceptación en un colegio y las notas de sus hijos dependen de sobornos, si su aceptación en un hospital y el tratamiento también dependen de aceptar cohechos y si los jueces dictan sentencia en función de lo que reciben de los políticos y enjuiciados entonces usted vive en un país de corrupción sistémica". 52
\end{abstract}

Si se trata de buscar un reflejo de estas situaciones en la realidad española, no se va a encontrar. Se aduce, por ello, que la corrupción no es sistémica, precisamente, por los datos en la experiencia directa de la corrupción, extraídos de encuestas de victimización. Estos datos permitirían, según los expertos, señalar que la corrupción en España se centra en un terreno más acotado, el de la corrupción política, ligada a la financiación de los partidos políticos, las campañas electorales ${ }^{53} \mathrm{y}$, de forma genérica, la relativa a la gestión del gasto público en gobiernos locales y autonómicos. Muy al contrario, me parece que no se puede obviar que los múltiples supuestos de corrupción política no se hubieran producido si no existiera una cierta relajación de los controles administrativos previos, que corresponden a determinados funcionarios ${ }^{54}$. Por ello, cabe plantearse que la corrupción política podría tener ciertos resortes en el sistema administrativo. En todo

\footnotetext{
${ }^{51}$ COX, Taylor, Cultural Diversity in Organizations - Theory, Research and practice, San Francisco: Berret-Koehler Publishers, 1993, pp. 185-200.

52 Vid. VILLORIA MENDIETA, Manuel, "Principales rasgos y características de la corrupción en España”, en: EL MISMO, GIMENO FELIÚ, y TEJEDOR BIELSA, La corrupción en España. Ámbitos, causas y remedios jurídicos, cit. nota ${ }^{\circ} 24$, p. 49.

53 Destaca la conversación de Ángel Fenoll, en el caso Brugal, puesto que el concejal de Orihuela Jesús Fernández únicamente le señalaba: "No quiero nada, tú paga la campaña". Para un contenido más exhaustivo de la conversación, Cadena Ser, 31 de marzo de 2006: http://www.cadenaser.com/articulo/espana/quiero/mangonear/detras/gusta\%85/alcalde/csrcsrpor/2006033 1csrcsrnac_2/Tes/. (Último acceso: 07/12/2016)

54 En este sentido, el estudio de la Fundación “¿Hay Derecho?” sobre "Corrupción y controles administrativos previos" destaca que una gran cantidad de casos de corrupción política no serían posibles sin la colaboración directa, la complicidad o sin el desistimiento o pasividad de los funcionarios o, en términos más generales, de los empleados públicos en sentido amplio.
} 
GUTIERREZ, Elena. “Corrupción pública: concepto y mediciones. Hacia el Public compliance como herramienta de prevención de riesgos penales".

caso, es cierto que la corrupción institucional considerada como la comisión de hechos delictivos cometidos por los propios funcionarios públicos no es la habitual ${ }^{55}$. Aunque no existan frecuentemente sobornos para la prestación de los servicios públicos, a mi juicio, no es indicador de que la corrupción no sea sistémica ${ }^{56}$. La corrupción está afincada a niveles más preocupantes en connivencia con el poder político ${ }^{57}$. La inexistencia de sobornos para la prestación de los servicios públicos es únicamente un síntoma de que en España no se da la corrupción más burda y cotidiana, pero no es óbice para concluir que la corrupción no es sistémica. Se podría catalogar como sistémica, si se pretende ser riguroso con las clasificaciones y categorías, la corrupción política en España. La corrupción política, como apunta Dopico Gómez-Aller, es "estructural y no coyuntural no sólo deriva de su persistencia y extensión, sino de la reiteración de pautas delictivas similares y de su vertebración por todo el territorio" $"$.

Considero que el concepto de corrupción sistémica está alojado en un umbral muy vasto de corrupción, el de la corrupción de "a pie de calle", pero olvida que el clima organizativo $^{59}$ tóxico existente es de proporciones gigantescas. ¿Acaso la corrupción política no es la más sistémica de todas? La corrupción política es ubicua y es tan porosa que se ha filtrado por el sistema de forma transversal ${ }^{60}$. En suma, la corrupción sistémica en el sentido mencionado ha generado un clima ético que se materializa en cómo las percepciones son compartidas en una organización de lo que es éticamente correcto y de cómo los dilemas éticos deben ser resueltos. La corrupción ha de ser entendida, en clave político criminal, como "la intencionada desnaturalización de las finalidades objeto de las instituciones públicas en beneficio patrimonial o simplemente de poder de un sujeto o grupo de sujetos"61. En consecuencia, se puede argumentar que la corrupción en España es sistémica en cuanto concurren tres notas: la habitualidad, permanencia y organización para su comisión. No se trata, como incide Queralt

\footnotetext{
${ }^{55}$ Resulta llamativo (y contradictorio) que el Departamento de Estado de Estados Unidos haya alertado, en su informe anual de derechos humanos en el mundo correspondiente a 2015, que uno de los tres principales problemas que padece España es la corrupción sistemática de funcionarios gubernamentales.

${ }^{56}$ En España, el ciudadano no paga un "extra" a la policía o por acceder a servicios públicos como la educación o la sanidad (a este fenómeno se le denomina petty corruption).

${ }^{57}$ En la administración local, no era anómalo que los secretarios de ayuntamiento e interventores que detectaran irregularidades en el procedimiento de contratación se limitaran «a dejarlas pasar, transcribiendo un "con reservas" o un "no intervengo" si se percatan, por ejemplo, de que el adjudicatario de una obra pública es un concejal del Ayuntamiento». Así lo pone de relieve JAREÑO LEAL, Ángeles, Corrupción y delincuencia de los funcionarios en la contratación pública, Madrid: Iustel, 2011, p. 183.

${ }^{58}$ DOPICO GÓMEZ-ALLER, Jacobo, "Aproximación a las necesidades de reforma legal en relación con la respuesta penal a la corrupción política”, Cuadernos penales José María Lidón, nº11, (2015), pp. 257284, p. 257.

${ }^{59}$ El concepto de clima organizativo es definido como «los efectos subjetivos, percibidos, del sistema formal de la organización y del estilo informal de los administradores y de otros factores ambientales importantes sobre las actitudes, creencias, valores y motivación de las personas que trabajan en una organización dada». Véase, LITWIN, George, y STRINGER, Robert, The influence of organizational climate, Cambridge: Harvard University Press, 1966, p. 26 y ss.

${ }^{60}$ Se transmite la idea de que la corrupción no tiene freno, está en todas partes, es un cimiento más del sistema. Es más, el sistema funciona con ella. Así lo admite incluso el empresario Enrique Ortiz en una entrevista concedida a El País cuando le preguntan acerca del trato de favor justificado a los políticos: Es el sistema. Yo no quería comprar el estadio del Hércules, por ejemplo. Pero había una presión social, que se traslada a que el político te diga: "Tienes que comprarlo.". Suplemento del Domingo, El País, 14 de noviembre de 2010, p. 3.

${ }^{61}$ QUERALT JIMÉNEZ, Joan Josep, "Public Compliance y corrupción: Análisis conceptual y propuestas", en Revista Internacional Transparencia e Integridad, n² (2016), pp. 1-11, p.3.
} 
Polít. crim. Vol. 13, № 25 (Julio 2018) Art. 3, pp. 104-143.

[http://www.politicacriminal.cl/Vol_13/n_25/Vol13N25A3.pdf]

Jiménez, de prácticas aisladas y esporádicas, sino de hechos que pretenden perdurar en el tiempo ${ }^{62}$.

\section{El Public Compliance como mecanismo para combatir la corrupción pública}

\subsection{Necesidad de un Public Compliance}

La carencia de controles preventivos en las Administraciones públicas ha contribuido a generar un caldo de cultivo ideal para los agentes corruptos. Frente a la incapacidad para detectar comportamientos corruptos en el propio seno de la organización, resulta llamativo que las corporaciones privadas se hayan visto incentivadas por el Estado a promover programas de cumplimiento normativo en sus organizaciones ${ }^{63}$, mientras que estas medidas de control preventivo no se han trasladado al ámbito de la Administración pública con la debida celeridad ${ }^{64}$. Parece evidente que, al margen de discusiones jurídicas, existe un cierto consenso en admitir que una sociedad no puede superar la corrupción recurriendo únicamente al Derecho Penal ${ }^{65}$. Por consiguiente, la estrategia frente a la corrupción en estos momentos no necesita más producción legislativa penal $^{66}$, sino técnicas que permitan aminorar las oportunidades delictivas y, en definitiva, los escenarios que faciliten comportamientos corruptos ${ }^{67}$. Y, para ello, se requiere mucho más que una revisión de tipos en el Código Penal ${ }^{68}$ y una aplicación forzada de la técnica del isomorfismo institucional, consistente en importar instituciones de otros países que pretenden paliar la corrupción. Las soluciones en esta materia deben llegar desde un diagnóstico profundo con análisis de riesgos que permitan representar la realidad del problema, que sirvan de base para la aplicación de técnicas de prevención

\footnotetext{
62 Ibídem, p.4.

63 Piénsese en la exención de responsabilidad penal a través de la adopción de un «modelo de organización y gestión» eficaz, tras la reforma por la LO 1/2015, de 30 de marzo, o, en el ámbito de la contratación pública, en la directiva de la Unión Europea sobre esta materia de 2014, que establece incentivos para que las corporaciones que contraten con la administración posean programas de cumplimiento. Véase, ampliamente, GÓMEZ-JARA DÍEZ, Carlos, "Responsabilidad penal de las personas jurídicas y contratación pública. A propósito de la nueva Directiva europea sobre contratación pública", Diario La Ley, no 8423 (2014).

${ }^{64}$ Hay autores que califican esta situación de "incoherente", ya que "el Estado, como organización, no adopta medidas similares a las que obliga a implantar a las empresas". Sobre la necesidad de aplicar una estrategia anticorrupción en la Administración, véase NIETO MARTÍN, "De la ética pública al public compliance: sobre la prevención de la corrupción en las administraciones públicas”, cit. nota n 20, p. 17.

65 DEL MORAL GARCÍA, Antonio, "Justicia penal y corrupción: déficits, resultados, posibilidades", Revista Vasca de Administración Pública, nº104 (2016), pp. 43-75, p. 44.

66 En este sentido, MEDINA ARNÁIZ, Teresa, "La necesidad de reformar la legislación sobre contratación pública para luchar contra la corrupción: las obligaciones que nos llegan desde Europa", Revista Vasca de Administración Pública, nº104 (2016), pp. 77-113, p. 81; DE LA MATA BARRANCO, "La lucha contra la corrupción política", cit. nota nº13, p. 22; QUERALT JIMÉNEZ, Joan Josep, "Diez acciones inmediatas contra la corrupción”, en CASTRO MORENO, Abraham, y OTERO GONZÁLEZ, Pilar, Prevención y tratamiento punitivo de la corrupción en la contratación pública y privada, Madrid: Dykinson, 2016, pp. 95-100, p. 95; DOPICO GÓMEZ-ALLER, "Aproximación a las necesidades de reforma legal en relación con la respuesta penal a la corrupción política”, cit. nota n57, p. 259.

${ }^{67}$ Este enfoque criminológico se traduce en que la aparición de conductas delictivas en cualquier organización se debe a técnicas de neutralización que proporcionan a sus miembros un contexto de justificación, que les lleva a la realización de conductas delictivas, al contrarrestar los valores de respeto a la legalidad, que el sujeto adquirió en su proceso de socialización.

${ }^{68}$ Respecto de la ausencia en nuestro proceso legislativo de una verdadera evaluación de los efectos de las leyes, vid. RODRÍGUEZ FERRÁNDEZ, Samuel, "La ¿evaluación? de las normas penales en España", $R E C P C, \mathrm{n}^{\circ} 15$ (2013), pp. 1-43, p. 20 y ss.
} 
GUTIERREZ, Elena. “Corrupción pública: concepto y mediciones. Hacia el Public compliance como herramienta de prevención de riesgos penales".

situacional que aumenten el riesgo percibido, procurando que la detección del delito sea más probable, incrementando el esfuerzo o, al menos, aparentar que es más arduo cometer el delito y, por ende, reducir los beneficios percibidos. Estas medidas deben ir complementadas de reformas extrapenales, ya que, de lo contrario, la regulación penal tendrá una efectividad testimonial ${ }^{69}$. Los datos que ayudan a trazar los contornos de la corrupción pública y construir controles que permitan identificar los comportamientos corruptos $^{70}$, como el nivel de la Administración en el que se ha cometido el delito, la tipología del infractor ya sea empleado público (funcionario, laboral o político), así como el ámbito de actuación en el que se produce, son caracteres esenciales para alcanzar conclusiones y que, sin embargo, han sido obviados. Se han aplicado políticas anticorrupción sin medir los efectos y evaluar los patrones de comportamiento ya existentes.

La prevención del delito puede orientarse a reducir las oportunidades para delinquir por medio del "diseño de personas", "diseño de lugares" y del "diseño de objetos"71. Tanto el primero como el segundo tienen una relevancia fundamental en el ámbito de la delincuencia en la Administración pública. Para el "diseño de personas" es necesario un programa que coordine, controle y gestione las oportunidades delictivas y, en la Administración, este programa tiene nombre propio: Public compliance. En cuanto al segundo, al "diseño de lugares", también desempeña un papel decisivo, si se entiende dirigido a la forma de construir la organización que, al fin y al cabo, es el lugar en el que se aplicarán técnicas de prevención situacional72. La idea que se persigue con las técnicas de prevención situacional, en el ámbito de la Administración pública, no es otra que, desde la perspectiva de la elección racional, estimular "sentimientos de consciencia en el momento en que el infractor contempla la posible comisión de una forma específica del delito"'73.

En las siguientes líneas se propone abordar la tarea de prevención de la corrupción desde el prisma de un Public compliance que genere un marco concreto en función de la fisonomía de la Administración. Este Public compliance estaría conformado por un mapa o análisis de riesgos, un procedimiento o canal de denuncias apropiado y

69 En este sentido, DOPICO GÓMEZ-ALLER, “Aproximación a las necesidades de reforma legal en relación con la respuesta penal a la corrupción política”, cit. nota n57, p. 259; DEL MORAL GARCÍA, "Justicia penal y corrupción: déficits, resultados, posibilidades", cit. nota n 64, p. 43 y ss.

${ }^{70}$ Acerca de la incidencia del carácter preventivo de los controles, MEDINA ARNÁIZ, "La necesidad de reformar la legislación sobre contratación pública para luchar contra la corrupción: las obligaciones que nos llegan desde Europa", cit. nota n67, p. 81. El Public Compliance vendría a traducirse en una estrategia anticorrupción basada en un cumplimiento público consistente en añadir a lo que desde los años 70 ' se conoce como ética pública, los contenidos del cumplimiento normativo desarrollado por las empresas. Sobre este concepto, NIETO MARTÍN, "De la ética pública al Public Compliance: sobre la prevención de la corrupción en las administraciones públicas", cit. nota n²0, p. 17.

${ }^{71}$ FELSON, Marcus, y CLARKE, Ronald: Business and Crime Prevention, Nueva York: Criminal Justice Press, 1997, p. 90.

${ }^{72}$ Sobre el concepto aplicado a la realidad empresarial, , Mateo, "Elección racional, oportunidad para delinquir y prevención situacional: la utilidad de este enfoque para el estudio de la delincuencia empresarial", en MIRÓ LLINARES, Fernando, AGUSTINA SANLLEHÍ, José, MEDINA SARMIENTO, José Eugenio, y SUMMERS, Lucia, (coords.), Crimen, oportunidad y vida diaria: libro homenaje al profesor Dr. Marcus Felson. Madrid, 2015, pp. 305-328, p. 317.

${ }^{73}$ Las técnicas de prevención situacional tienen como finalidad la reducción de oportunidades para cometer el delito, a través de la modificación del entorno en el que este acontece. Más ampliamente, CLARKE, Ronald, "Situational crime prevention: Its theoretical basis and practical scope", Crime and Justice: An annual review of research, $\mathrm{n}^{\circ} 4$ (1983), pp. 91-150. 
Polít. crim. Vol. 13, № 25 (Julio 2018) Art. 3, pp. 104-143.

[http://www.politicacriminal.cl/Vol_13/n_25/Vol13N25A3.pdf]

organismos de control interno y externo ${ }^{74}$. Para lograr esta finalidad, se pretende importar elementos e instituciones propias de los programas de cumplimiento en las empresas a las estructuras de las Administraciones públicas, si bien para lograr este propósito es necesario que se reformulen ciertas instituciones.

\subsection{Propuesta de Public Compliance desde un prisma criminológico. Los corporate compliance como punto de referencia}

Para explicar el fenómeno de la corrupción, desde las teorías económicas, se ha recurrido a la teoría principal-agente (o teoría de la agencia) de Klitgaard, que todavía hoy cobra relevancia:

"La corrupción es el abuso de posición para beneficio personal. La posición se refiere a un puesto desempeñado, para el que se otorga una autoridad sustentada en la confianza de un principal, en el que el actor que lo desempeña (agente) debe actuar en beneficio de tal principal (sea la ciudadanía, los accionistas o los miembros de la asociación) y no en beneficio propio" ${ }^{75}$.

La aplicación de la teoría de la agencia al control de la corrupción se traduce en el análisis de las condiciones que generan incentivos en los comportamientos corruptos de los individuos. La teoría de la agencia ha sido habitualmente aplicada en el terreno de la organización de empresas, sin embargo, las piezas del funcionamiento de una empresa pueden, a mi juicio, ser extrapolables, con matices, al campo de la Administración pública. La máxima de esta teoría requiere de un principal (en nuestro caso, Administración pública en sentido abstracto que defiende unos intereses públicos) que necesita de un agente (empleados públicos, ya sean funcionarios, laborales o políticos) para relacionarse con sus clientes (la ciudadanía) ${ }^{76}$.

La corrupción es "un crimen de cálculo, no un crimen pasional" y, esta nota característica nos conduce al terreno de la teoría de la elección racional, de los beneficios y costes percibidos por el potencial delincuente que pondera si llevará a cabo el delito. La teoría de la elección racional se plasma en la idea de que la conducta delictiva deriva de un proceso racional de toma de decisiones en el que el sujeto actúa con una determinada finalidad eligiendo entre las opciones que posee ${ }^{77}$. Con este contexto de fondo, la estrategia anticorrupción se orientaría a la reducción de los incentivos que se encuentran los sujetos que interactúan en las Administraciones públicas. En la teoría del agente-principal se identifican dos situaciones en los que la actuación fraudulenta se instala en la estructura organizativa: la selección adversa y el

\footnotetext{
74 DÍEZ, José Enrique, y TORIJA HERRERO, Susana, proponen como elementos un mapa de riesgos, un código de conducta, formación y comunicación, un canal de denuncias, procedimientos de denuncia, una oficina anticorrupción y criterios de respuesta. Al respecto, "Modelo de estrategia para fomentar la integridad y prevenir la corrupción", Revista de Transparencia e Integridad, n² (2016), pp. 1-23, p. 6 y SS.

75 KLITGAARD, Robert, MACLEAN-ABAROA, Ronald, y PARRIES, Lindsey: A practical approach to dealing with municipal malfeasance, Workshop Papers nº7, Wikibezkorupce website, 1998, p. 1.

${ }^{76} \mathrm{El}$ autor ha realizado aplicaciones prácticas a su teoría en varios trabajos de consultoría para el Banco Mundial y también para administraciones públicas. Un ejemplo de ello fue el ayuntamiento de La Paz (Bolivia).

${ }^{77}$ CLARKE, Ronald, y FELSON, Marcus, "Criminology, routine activity and rational choice", en LOS MISMOS, Routine activity and rational choice. Advances in Criminological Theory, $\mathrm{n}^{\circ} 5$, New Brunswick: Transaction Publishers, 1993, pp.1-14.
} 
GUTIERREZ, Elena. “Corrupción pública: concepto y mediciones. Hacia el Public compliance como herramienta de prevención de riesgos penales".

riesgo moral $^{78}$. En la primera situación se selecciona al agente que actuará en nombre del principal. Los agentes seleccionados son inadecuados — de ahí que se denomine selección adversa - para que actúen en nombre del principal. En la Administración pública, el paradigma de selección adversa lo constituye los cargos de libre designación. En la segunda situación, la de riesgo moral, el agente actúa en nombre del principal sin que éste tenga un conocimiento completo de todas las acciones de aquél. El agente, en este escenario, aprovecha esta situación para realizar actividades que son contrarias a los intereses del principal. El riesgo moral en el caso español residiría en los controles preventivos ineficientes. Esta teoría de la agencia trasladada al ámbito de la corrupción en la Administración vendría a tratar de atajar procesos de selección, mayoritariamente de designación política, que no responden a los intereses públicos de la propia Administración (principal). Los partidarios de la teoría de la agencia construyen los mecanismos anticorrupción a través de un control tanto ex ante como ex post ${ }^{79}$.

En el sector público, las lagunas en el diseño institucional, el monopolio y discrecionalidad del agente (empleado público o cargo político), sin instituciones específicas que promuevan la imparcialidad, así como la rendición de cuentas, generan múltiples oportunidades de que el agente actúe en beneficio propio y no por el propio principal $^{80}$. Los agentes corruptos, como actores racionales, miden cómo los demás van a actuar. De esta manera, si existe una creencia generalizada de que la mayoría de los ciudadanos actúa corruptamente y, además, con impunidad, los incentivos para actuar de forma reprochable se multiplican ${ }^{81}$. Las teorías de la agencia incurren en un error: presuponen que el principal siempre va a estar interesado en controlar al agente para que actúe en defensa de sus intereses $\mathrm{y}$, en suma, no contemplan al principal "sin principios" $" 82$.

\footnotetext{
78 Sobre la aplicación de esta teoría al ámbito del control de la corrupción pública, véase JIMÉNEZ SÁNCHEZ, Fernando, "La trampa política: La corrupción como problema de acción colectiva", en PASTOR SELLER, Enrique, TAMEZ GONZÁLEZ, Gerardo, y SÁENZ LÓPEZ, Karla, Gobernabilidad, ciudadanía y democracia participativa: análisis comparado España-México, Madrid: Dykinson, 2014, pp. 157-174, p. 161 y ss.

${ }^{79}$ Con los mecanismos ex ante se trata de reducir el riesgo de seleccionar agentes que tengan una probabilidad alta de corromper la relación de agencia poniendo sus propios intereses por encima de los del principal. De forma muy esquemática se hace referencia a instrumentos que permitan mejorar la información de la que dispone el principal sobre los posibles candidatos a actuar como sus agentes. El propósito es determinar cuál de estos potenciales candidatos podría, según su perfil, tener unas tendencias que antepongan los intereses privados a los públicos. La segunda medida ex ante está relacionada con el modelo de disuasión y la certeza de las sanciones. Se refiere a la implantación de sanciones para penalizar a los agentes corruptos de forma eficaz y certera, no sólo sobre el papel. La probabilidad de que las sanciones se apliquen tiene indudables beneficios, pues permitirá que muchos potenciales candidatos a corruptos decidan no traicionar la confianza de las instituciones. Como medidas ex post se incluyen toda una amalgama relacionada con la transparencia que permiten detectar conductas irregulares. Sobre la cuestión, JIMÉNEZ SÁNCHEZ, Fernando, “La trampa política...”, cit. nota nº79, p. 161.

80 GRAYCAR, Adam y VILLA, Diego, «The loss of governance capacity through corruption», Governance, $\mathrm{n}^{\circ} 24$ (2011), pp. 419-438.

${ }^{81}$ Un estudio reciente que ilustraría esta situación es el de la corrupción urbanística de las Islas Canarias, ya que pese a que se establecieron políticas territoriales para impedir una especulación sobre el suelo y mantener los recursos naturales de las islas, se incumplió la normativa mediante corrupción y clientelismo. Acerca de los límites de la teoría del principal-agente y el dilema colectivo, VILLORIA MEDIETA e IZQUIERDO, Ética publica y buen gobierno. Regenerando la democracia y luchando contra la corrupción desde el servicio público, cit. nota $\mathrm{n}^{\circ}$ 5, pp. 306-310.

82 PERSON, Anna, ROTHSTEIN, Bo, y TEORELL, Jan, "Why anticorruption reforms fail. Systemic corruption as a collective action problem”, en Governance, n²6 (2013), pp. 449-471.
} 
Polít. crim. Vol. 13, № 25 (Julio 2018) Art. 3, pp. 104-143.

[http://www.politicacriminal.cl/Vol_13/n_25/Vol13N25A3.pdf]

Para un análisis certero de riesgos no se puede obviar los relevantes componentes teóricos que aporta la criminología. La Administración, entendida en términos de la teoría de elección racional, no deja de constituirse, pese a su carácter público, como una estructura organizacional que suministra oportunidades para cometer delitos (hot spots). La ponderación de costes/beneficios que realizan los corruptos conecta con el modelo conceptual de la elección racional, si bien se ha de considerar las singularidades de la delincuencia en la Administración pública tomando ciertos elementos básicos de este modelo que ya extrapolaron Paternoster y Simpson a la realidad empresarial ${ }^{83}$. El modelo propuesto parte de la teoría de la elección racional de la criminología en los siguientes aspectos: i. La decisión de delinquir depende de los costes y beneficios esperados (percibidos) por el infractor potencial: los costes del delito incluyen la severidad y probabilidad de las sanciones jurídicas; ii. Los modelos de la elección racional deberían ser específicos para cada clase de delito debido a que el tipo de información necesitada y utilizada por los infractores varía considerablemente según el delito de que se trate; iii. La decisión de delinquir en una circunstancia específica (el evento delictivo) se ve afectada por las características del contexto inmediato del delito $^{84}$.

A la vista de lo expuesto, puede subrayarse que la Teoría de las Actividades Cotidianas (en adelante, TAC) podría ser un relevante soporte para construir controles previos frente a la corrupción. Esta teoría podría sintetizarse en la existencia de un delincuente motivado, con un objetivo apropiado para ser victimizado que, en ausencia de guardianes capaces de prevenir el delito, puede constituir una oportunidad para un delito $^{85}$. En el supuesto de la corrupción pública, esta teoría debe ser matizada, al poseer ciertas singularidades que se justifican por el tipo de ente público. El objetivo apropiado o la víctima en materia de corrupción en la Administración pública es difusa. No existe una víctima directa e individual, contribuyendo a la existencia de una cifra negra. La víctima no se personifica, sino que es un ente abstracto como es la Administración pública y el interés general. En consecuencia, la capacidad para potenciar los sentimientos de culpabilidad asociados a la realización del comportamiento criminal se advierten complejos ${ }^{86}$. Asimismo, la ausencia de guardianes capaces que indica la TAC no tiene por qué necesariamente centrarse en "figuras de policía", de control formal, sino que es la potencialidad de otros actores de denunciar irregularidades en la propia administración, el control informal, lo que provoca un descenso de oportunidades delictivas y un aumento de la percepción a ser detectado.

2.2.1 Identificación y clasificación de riesgos: nuevo enfoque y problemas

${ }^{83}$ PATERNOSTER, Raymond, y SIMPSON, Sally, "A rational choice theory of corporate crime», en CLARKE, Ronald, y FELSON, M., Routine Activity and rational choice. Advances in criminological theory, Londres: Transaction Publishers, 1993, pp.41-42.

${ }^{84}$ BERMEJO, "Elección racional, oportunidad para delinquir y prevención situacional: la utilidad de este enfoque para el estudio de la delincuencia empresarial", cit. nota $\mathrm{n}^{\circ} 73$, p. 311.

${ }^{85}$ COHEN, Lawrence, y FELSON, Marcus, "Social change and crime rate trends: A routine activity approach", en ASR, vol. 44, nº (1979), pp. 588-608.

${ }^{86}$ Aunque anecdótico, sí puede resultar indicativo de la falta de conciencia que existe en los delitos contra la Administración Pública que la abogada del Estado en el caso "Noós" declarase que "Hacienda no somos todos", sino que era un lema meramente publicitario. Véase la noticia sobre este procedimiento judicial en El Mundo, 11 de enero de 2016. Disponible en: http://www.elmundo.es/baleares/2016/01/11/5693a093ca4741106e8b4607.html (Último acceso 14/05/2017). 
GUTIERREZ, Elena. “Corrupción pública: concepto y mediciones. Hacia el Public compliance como herramienta de prevención de riesgos penales".

No se han puesto los instrumentos y medios para abordar una materia tan relevante como el análisis de riesgos en la Administración pública. Es obvio que para prevenir hay que identificar, en primer término, el origen del déficit. Y, sin embargo, mientras que en las corporaciones privadas se han ido instaurando técnicas y metodologías más sofisticadas para llevar a cabo los análisis de riesgos ${ }^{87}$, en las Administraciones públicas sólo existen procedimientos de control que han quedado obsoletos, incapaces de detectar la corrupción.

En este punto conviene ofrecer una panorámica del estadio de la Administración en el que se produce la corrupción y, en mayor detalle, en qué esferas competenciales. La división de la Administración en España en tres niveles interesa para determinar si en todos estos niveles se detecta la corrupción pública de igual manera. La respuesta es rotunda: no existe una corrupción pública homogénea. Las Administraciones locales concentran el grueso de la corrupción. Se identifica que a nivel europeo las Administraciones más permeables a la corrupción, por poseer unos controles más débiles que los de la administración central y disponer de unos incentivos más propicios para que se produzca, son las Administraciones locales ${ }^{88}$. ¿Pero existen datos objetivos que confirmen estas aseveraciones en España? Un estudio privado analizó, en el periodo 2011-2014, un total de 330 condenas, seleccionadas sobre delitos característicos de la corrupción pública ${ }^{89}$, confirmando que el entramado corrupto tiene mayores resortes en el nivel de la Administración local $-48,5$ por ciento frente a un 27 por ciento de la Administración General del Estado ${ }^{-90}$. Precisamente lo relevante del estudio es que permite hilar fino, hacia el detalle de qué cargo o puesto ostentaban los condenados implicados en estos delitos y el nivel de la Administración pública en el que se produjo. Este dato no consta en ninguna fuente pública u oficial.

En cuanto a la corrupción en las Comunidades Autónomas, de las 330 resoluciones analizadas, se observa que las más numerosas se refieren a delitos de corrupción en Administraciones públicas de Andalucía (un 27,7 por ciento), Baleares (12,4 por ciento) y Cataluña (10 por ciento). El European Quality of Government Index (EQI), indicador de la calidad de gobierno en 206 regiones de 24 países europeos, muestra que las comunidades españolas con mejores resultados (Asturias, Cantabria, País Vasco o La Rioja) obtienen un resultado similar a la media europea, mientras que aquellas que obtienen una peor puntuación (Canarias, Extremadura, Comunidad Valenciana o Galicia), se encuentran en la zona media-baja del índice ${ }^{91}$. Esta mayor permeabilidad a la corrupción en las Administraciones locales y autonómicas puede explicarse en atención al grado de discrecionalidad de las decisiones, así como en un mayor peso de la provisión de cargos de libre designación, a los que se añade el libre cese y, a mayor abundamiento, la dependencia salarial y profesional de los encargados del control, como la figura de los interventores.

\footnotetext{
87 A título de ejemplo, se pueden citar la UNE-EN 31010:2011. Gestión del riesgo. Técnicas de apreciación del riesgo, UNE-ISO 31000:2010. Gestión del riesgo. Principios y directrices, UNE 19601 Sistemas de gestión de compliance penal.

${ }^{88}$ EU Anti-corruption report, COM (2014), de 3 de febrero 2014.

${ }^{89}$ Se seleccionaron los delitos de tráfico de influencias, soborno, prevaricación de los funcionarios públicos y malversación de fondos públicos.

90 Informe de la Fundación ¿Hay Derecho? «Corrupción institucional y controles administrativos preventivos», marzo de 2015.

${ }^{91}$ Documento para el debate "Corrupción y calidad democrática", Círculo de Economía de Barcelona, noviembre de 2015.
} 
Cobra una especial importancia el ámbito de la actuación administrativa en el que se manifiesta la corrupción. El núcleo se concentra en actividades en las que la legislación administrativa permite un mayor grado de discrecionalidad. Si se analizan los ámbitos de actuación en los que se localizan casos de corrupción en la muestra de las 330 sentencias, en función del nivel territorial de la Administración, se observa un dato muy relevante: los casos de corrupción en materia de contratación se dan exclusivamente en los niveles local y autonómico, y especialmente en el primero, a pesar de que la contratación, lógicamente, se produce en todas las Administraciones. Se estima que los pocos supuestos registrados en el ámbito de la AGE se deben a la existencia de unos controles administrativos más estrictos. Las condenas por delitos de corrupción se concentran en el ámbito de la contratación del sector público, en el que se han producido un total de 31,4 por ciento de los delitos. Si bien también existe una relevante cifra focalizada en el ámbito del urbanismo ${ }^{92}-16,5$ por ciento- $\mathrm{y}$, de forma más distante, en los procedimientos de autorización, revisión e inspección, en las subvenciones $-4,4$ por ciento- y en los procedimientos para la contratación y selección del personal -3,7 por ciento-. La corrupción urbanística en España se contabilizó en un estudio, entre los años 2000 y 2010, en 676 municipios, rozando un 8,3 por ciento del total de los Ayuntamientos en España ${ }^{93}$. Esta cifra de la media nacional se dispara si se focaliza en determinadas Comunidades Autónomas como Murcia -57,8 por ciento-, Canarias $-39,8$ por ciento-, Baleares $-35,8$ por ciento-, Asturias $-26,9$ por ciento- ${ }^{-}$ Madrid $-25,7$ por ciento- .

En el ámbito de la Administración pública, el control de riesgos se confía a normas de carácter general, como las de conflictos de interés, las incompatibilidades, las leyes de transparencia y buen gobierno o códigos éticos generales ${ }^{94}$. Pero por más que se recurra a la inflación de normativa ${ }^{95}$, ésta no va a convertirse en un método suficiente. No se trata tanto de instaurar códigos éticos que relacionen las cualidades ideales que deben poseer los empleados públicos ${ }^{96}$, sino de diseñar controles para que se cumplan ${ }^{97}$. Si bien es cierto que hay quienes consideran que estos códigos éticos constituyen la piedra angular del cumplimiento normativo, ya que su función precisamente sería contrarrestar que el sujeto aprenda nuevos valores en el seno de la organización que le incitaran a

\footnotetext{
92 La razón más probable de este foco de corrupción se fundamenta en el dato de que el urbanismo se convirtió desde mediados de los años 90 en el motor de la economía del país. En recientes estudios doctrinales se ha determinado que los autores principales de las tramas de corrupción en urbanismo eran aquéllos que a su respectiva condición de particulares o funcionarios aunaban un cargo político (alcaldes, concejales y personal de confianza de estos últimos). Para una mayor exhaustividad sobre la corrupción urbanística, GÓRRIZ ROYO, Elena, "Corrupción urbanística: Análisis criminológico y respuestas jurídico-penales”, en JAREÑO LEAL, Ángeles, Corrupción pública: Cuestiones de política criminal (I), Madrid, 2014, pp. 89-148, pp. 139 y ss. Sobre la corrupción urbanística y como prevenirla, vid. TEJEDOR BIELSA, “La corrupción urbanística. Un problema sistémico", cit., nota n²4, pp. 331 y ss.

93 JEREZ DARIAS, Luis, MARTÍN MARTÍN, Víctor y PÉREZ GONZÁLEZ, Ramón, “Aproximación a una geografía de la corrupción urbanística en España”, Ería, no 87 (2012), pp. 5-18.

94 Además de la ley de carácter estatal que contempla el código de conducta, también existen códigos de conducta de ámbito territorial más específicos, para regular el comportamiento de los empleados públicos en varias comunidades autónomas.

95 España multiplica por diez las disposiciones normativas que tiene Alemania. SEBASTIÁN GASCÓN, Carlos, España estancada. Por qué somos poco eficientes, Barcelona: Galaxia Gutenberg, 2016.

${ }^{96}$ Capítulo VI del Título III de la Ley 7/2007, de 12 de abril, del Estatuto Básico del Empleado Público, que contiene el Código de Conducta de los empleados públicos.

97 De alguna manera ya se llevó a cabo en otras materias como la prevención de riesgos laborales, blanqueo de capitales o abuso de mercado.
} 
GUTIERREZ, Elena. “Corrupción pública: concepto y mediciones. Hacia el Public compliance como herramienta de prevención de riesgos penales".

cometer hechos delictivos $^{98}$, lo que parece incuestionable es que sin complementos no tendrán repercusiones positivas.

Conviene matizar que de la misma forma que un plan de cumplimiento no será idéntico en una PYME que en una multinacional, tampoco se puede pretender realizar un plan homogéneo con las Administraciones públicas, ya que existen múltiples estructuras (organismos autónomos, diputaciones, ayuntamientos, sociedades mercantiles públicas, comunidades autónomas, etc.) con singularidades que requieren controles especializados. No sólo diferenciando el nivel de la Administración ${ }^{99}$, pues incluso en distintas zonas geográficas los riesgos pueden ser distintos ${ }^{100}$. El mapa de riesgos debe desglosar las áreas más sensibles con una calificación de "alto", "medio" y "bajo", en referencia al riesgo penal en determinados ámbitos de actuación. Para su elaboración no sólo deberán tenerse en consideración factores internos, como los déficits legislativos o los mecanismos de control, sino también factores externos que incluyen las organizaciones o personal externo con el que los empleados públicos se relacionan en sus funciones. Se trata de invertir en prevención, algo hasta estos momentos impensable en la Administración pública, que sólo actuaba de forma reactiva al delito.

Otro de los grandes problemas en torno al análisis de riesgos se centra en el organismo o entidad que debería ocuparse de tal labor. Las Administraciones públicas manejan datos sensibles y ello provoca que existan reticencias cuando se propone la externalización del servicio. Así lo concibe la legislación italiana que casi prohíbe que personas ajenas a la Administración lleven a cabo análisis de riesgos o participen en su elaboración ${ }^{101}$. Para Nieto Martín, quien abunda en que el análisis por órganos externos es avalado por el Comitte on Standards in Public Live, la mayor parte de las Administraciones necesitarán contar con personal externo tanto en la fase de análisis como en la de revisión ${ }^{102}$. En España, el control por órganos ajenos a la Administración no es habitual, sin embargo, el Tribunal de Cuentas se sometió por primera vez, en fechas recientes, a una peer review o revisión entre pares por parte del Tribunal Europeo

98 Sería una aplicación a este ámbito de la teoría de la asociación diferencial de Sutherland, SUTHERLAND, E. H.: Principles of Criminology, $4^{\mathrm{a}}$ ed., Filadelfia: J.B. Lippincott, 1947.

${ }^{99}$ El Consello de contas gallego incluye en su plan de trabajo de 2017 una evaluación e implantación de los sistemas de control interno y de gestión de riesgos en las entidades locales del tramo de población de 10.001 a 20.000 habitantes. Puede consultarse el Plan de Trabajo completo para el ejercicio 2017: http://www.consellodecontas.es/sites/consello_de_contas/files/contents/documents/2017/Plan_traballo_20 17_C.pdf (Último acceso: 18/01/2017)

100 Piénsese en el urbanismo en las Islas Canarias, Islas Baleares o Comunidad Valenciana, donde especialmente en zonas aptas para el turismo el riesgo de que se produzcan irregularidades en este campo será más elevado.

101 En Italia, la Legge Anticorruzione n.190/2012, en su art. 1.9, concreta que cada responsable anticorrupción ha de elaborar un mapa de riesgos plasmado en lo que denominan "plan trienal" que abarca los siguientes elementos: i. Las actividades en que resulta más elevado el riesgo de corrupción; ii. Establecer la forma en que han de desarrollarse las actividades en las que se ha detectado un riesgo de corrupción señalando el procedimiento que debe adoptarse y los mecanismos de control; iii. Indicar las obligaciones de información a los responsables anticorrupción de cada entidad; iv. V. Mecanismos de supervisión relativos al respeto a las condiciones, previstas en la ley o los reglamentos, para la realización de estos procedimientos; vi. contratistas o aquellas personas que están interesadas en autorizaciones, concesión de ventajas económicas; vii. Señalar mecanismos de transparencia adicionales a los previstos en la ley. Para una comparativa sobre la Legge Anticorruzione, vid. NIETO MARTÍN, "De la ética pública al public compliance: sobre la prevención de la corrupción en las administraciones públicas”, cit., nota $\mathrm{n}^{\circ} 20$, pp. $31 \mathrm{y}$ ss.

102 NIETO MARTÍN, “De la ética pública al Public Compliance: sobre la prevención de la corrupción en las administraciones públicas", cit. nota n²2, p. 36. 
Polít. crim. Vol. 13, № 25 (Julio 2018) Art. 3, pp. 104-143.

[http://www.politicacriminal.cl/Vol_13/n_25/Vol13N25A3.pdf]

de Cuentas y su homólogo portugués, por lo que parece indicar que el análisis por órganos externos empieza a considerarse como una opción para identificar áreas de mejora $^{103}$.

Una alternativa viable es el análisis de riesgos por parte de las denominadas Agencias antifraude, de prevención y lucha contra la corrupción. Las Agencias de la Comunidad Valenciana y las Islas Baleares ya mencionan, entre sus funciones, llevar a cabo estudios y análisis de riesgos previos en actividades relacionadas con la contratación administrativa, prestación de servicios públicos, ayudas o subvenciones públicas y procedimientos de toma de decisiones ${ }^{104}$. Sumamente positiva considero la alusión que hace la legislación valenciana a la colaboración en esta materia con los servicios de auditoría o intervención y, en especial, el estudio que se realizará de los informes a que se refiere el art. 218 del Real decreto legislativo 2/2004, por el que se aprueba el Texto Refundido de la Ley reguladora de Haciendas Locales, de los cuales la intervención enviará una copia anual a la agencia y la evaluación de su traslado a la fiscalía anticorrupción.

\subsubsection{El interventor como compliance officer en la Administración}

La identificación y clasificación de los riesgos es una tarea previa y dinámica esencial para poder acometer la actividad de prevención. Pero aún más relevante es institucionalizar el control y la supervisión de determinadas áreas de riesgo. Resulta estéril establecer áreas de riesgo si nadie comprueba que va a haber un incumplimiento o éste ya se ha producido ${ }^{105}$. En órgano supervisor del funcionamiento del programa de cumplimiento normativo en las corporaciones privadas recae sobre el compliance officer o la unidad de cumplimiento normativo. Cabe plantearse quién o quiénes podrían

${ }^{103}$ La revisión entre pares hace referencia a una evaluación realizada al Tribunal por parte de otros tribunales tras la que se realizan recomendaciones de mejora. Se trata de una práctica común en este tipo de organismos y que en el caso español se ha realizado por primera vez este año. Sobre el particular, véase el interesante Informe de la Fundación "Hay Derecho": "Análisis del funcionamiento del Tribunal de Cuentas. Comparativa Europea», presentado el 2 de octubre de 2015 en la sede del Parlamento Europeo en España. http://hayderecho.com/wp-content/uploads/2016/09/FHD-AnalisisTribunalCuentasVF.pdf Último acceso: 28/11/2016

104 Art. 5 c) apartado $1^{\circ}$ de la Ley 16/2016, de 9 de diciembre, de creación de la Oficina de Prevención y Lucha contra la Corrupción en las Illes Balears: $1 .^{\circ}$ Llevar a cabo estudios y análisis de riesgos previos en actividades relacionadas con los contratos, las ayudas o las subvenciones públicas, incluidos en el ámbito de aplicación de esta ley, que permitan hacer la inspección o el seguimiento de dicha actividad. Art. 4 apartado E) de la Ley 11/2016, de 28 de noviembre, de la Agencia de Prevención y Lucha contra el Fraude y la Corrupción de la Comunitat Valenciana: Hacer estudios y análisis de riesgos previos en actividades relacionadas con la contratación administrativa, la prestación de servicios públicos, las ayudas o las subvenciones públicas y los procedimientos de toma de decisiones, en colaboración con los servicios de auditoría o intervención. En particular, estudiará los informes a que se refiere el art. 218 del Real decreto legislativo 2/2004, por el que se aprueba el texto refundido de la Ley reguladora de Haciendas Locales, de los cuales la intervención enviará una copia anual a la agencia y la evaluación de su traslado a la fiscalía anticorrupción.

105“De poco sirve todas las medidas planteadas sobre la "sostenibilidad presupuestaria", una política de "racionalización y contención del gasto", el "adelgazamiento" de las Administraciones Públicas, la reforma del modelo de la planta local, la "funcionarización" de la función pública, la aprobación de una Ley de Transparencia, etc., si no hay voluntad de actuar sobre el corazón del sistema, esto es, el control interno local por funcionarios cualificados e independientes", así lo reclamaban URRUTICOECHEA BASOZABAL, Fernando, y ORTIZ GARCÍA, Mercedes, "La racionalización y sostenibilidad de la administración local mediante el fomento de su control interno a través de la recuperación de la independencia de los interventores municipales" en la Comunicación presentada al VIII Congreso de la AEPDA, Alicante, febrero 2013. 
GUTIERREZ, Elena. “Corrupción pública: concepto y mediciones. Hacia el Public compliance como herramienta de prevención de riesgos penales".

adoptar o reforzar las cualidades de esta figura en el ámbito público. Sobre este particular, se propone, en lugar de crear nuevas figuras en la Administración, la reformulación de algunas ya existentes, que están debilitadas, con una serie de singularidades ${ }^{106}$.

La institucionalización del órgano que deba ocuparse de las labores de supervisión, cumplimiento y funcionamiento en la Administración pública es uno de los grandes problemas, pues se aduce que la creación de nuevas figuras supondría una hipertrofia de organismos. Una propuesta, a mi juicio, que podría salvar este obstáculo en las entidades locales, acorde con el principio de economía organizativa que impera, es la atribución de estas funciones a los interventores ${ }^{107}$. Este cuerpo creado en 1924, precisamente para poner fin al caciquismo territorial, se encarga de controlar la gestión económico-financiera de las Administraciones locales, fiscalizando los gastos e ingresos ${ }^{108}$. De facto se ha podido apreciar como los interventores han ido destapando una multitud de supuestos de corrupción con el efecto pernicioso de ser estigmatizados $^{109}$. La figura del interventor, que inicialmente dependía del Estado, se convirtió, como corolario de la autonomía local de los Ayuntamientos, en dependiente orgánica, funcional y salarialmente de los consistorios. Este cuerpo perdía su independencia, una nota que caracterizaba a los cuerpos estatales, a lo que se añadía la posibilidad contemplada de su libre designación por cada Ayuntamiento. Pese a que a su libre designación fue planteada como un aspecto que podría rozar la inconstitucionalidad, la STC 235/2000 la declaró constitucional en una no menos controvertida resolución ${ }^{110}$. El propio Tribunal de Cuentas ha manifestado, en un buen

106 Algún autor propone la creación de una figura con atribuciones propias, apuntando que "aunque puedan serlo profesionalmente, los compliancer no son ni juristas ni economistas ni hacendistas. Ni informan, ni dictaminan ni ejecutan. Velan por la integridad de su ente de forma independiente". Véase, QUERALT JIMÉNEZ, "Public Compliance y corrupción: Análisis conceptual y propuestas", cit., nota n 61 , p. 6

${ }^{107}$ Se ha utilizado la expresión economía organizativa para hace referencia a la deseable evitación de nuevos organismos públicos cuando es posible atribuir esas funciones a un organismo o institución en funcionamiento que fácilmente las pudiera asumir. Sobre el particular, aplicado a la necesidad de un organismo de control de la integridad en materia de contratación pública, CERRILLO i MARTÍNEZ, Andrés, El principio de integridad en la contratación pública. Mecanismos para la prevención de los conflictos de intereses y la lucha contra la corrupción, Cizur Menor: Aranzadi, 2014, p. 331.

${ }^{108}$ Para NIETO GARCÍA "la fórmula era teóricamente impecable y estos funcionarios pudieron cortar en seco las tentaciones locales de corrupción y caciquismo", pero precisamente ese éxito era lo que los convertía en incómodos y apenas iniciada la transición democrática se desmanteló su funcionamiento y el éxito los "arrastró a su perdición". Véase, NIETO GARCÍA, El desgobierno de lo público, cit., nota no 3, pp. 291 y ss.

${ }^{109}$ Un ejemplo visible, Maite Carol, la que fuera interventora del Ayuntamiento de Santa Coloma de Gramanet, denunció presiones del alcalde implicado en el Caso Pretoria y fue cesada precisamente por presentar informes que advertían de las ilegalidades cometidas por el Ayuntamiento con empresas privadas. Véase, en prensa, "Maite Carol, el origen del 'caso Pretoria"': "Me dije: me iré a vender barras de pan, pero no me callo". Noticia publicada en lainformacion.com el 19 de septiembre de 2015. Otro caso llamativo es el de Fernando Urruticoechea, quien ha destapado durante más de dos décadas irregularidades cometidas en las entidades locales en las que ha ejercido de interventor. Sobre estos casos, en prensa, disponible en: http://noticias.lainformacion.com/heroes-contra-la-corrupcion/maite-carol-elorigen-del-caso-pretoria-me-dije-me-ire-a-vender-barras-de-pan-pero-no-me

callo_YajYDfNnwv0bZIqHfE6176/ (Último acceso 25/04/2017)

${ }^{110} \mathrm{Se}$ declaró la constitucionalidad del precepto sobre la base del historial profesional en el caso concreto de los aspirantes. El voto particular del magistrado Pablo García Manzano señala la incoherencia de este sistema: "implica que el ámbito de neutralidad e imparcialidad aparece así menoscabado ante el riesgo cierto de pérdida de la confianza del órgano monocrático que lo nombró, y consiguiente cese en las 
Polít. crim. Vol. 13, № 25 (Julio 2018) Art. 3, pp. 104-143.

[http://www.politicacriminal.cl/Vol_13/n_25/Vol13N25A3.pdf]

número de informes sobre las corporaciones locales, que la dependencia ha convertido a los "controlados" en los propios "supervisores", pues son los que realmente influyen en sus condiciones laborales.

Sin embargo, la Ley 27/2013, de 27 de diciembre, de racionalización y sostenibilidad de la Administración Local pretendía, según su Preámbulo, reforzar la independencia del cuerpo de interventores, ya que "a partir de ahora el Gobierno fijará las normas sobre los procedimientos de control, metodología de aplicación, criterios de actuación, así como derechos y deberes en el desarrollo de las funciones públicas necesarias en todas las Corporaciones locales" y abundaba en la idea de independencia: "corresponde al Estado su selección, formación y habilitación así como la potestad sancionadora en los casos de las infracciones más graves". No obstante, esta última asunción ha llevado a constituirse en una mera formalidad, más cosmética que real. Un ejemplo más de lo que se ha denominado lampedusismo ${ }^{111}$. Los interventores, en el plano formal, pertenecen al Estado mediante los nombramientos, plazas vacantes y concursos, pero lo cierto es que se continúan manteniendo las dos notas características más dañinas: las condiciones salariales dependen del Ayuntamiento y se perpetúa la libre designación ${ }^{112}$. La libre designación en un cargo tan relevante como la fiscalización del gasto público en las corporaciones locales no deja de resultar inquietante, ya que entre interventores y alcaldes se generan vínculos de gratitud, confianza o dependencia en detrimento del interés general ${ }^{113}$. Los interventores, en lugar de concurrir por méritos a los municipios pueden ser designados libremente por cada Ayuntamiento simplemente cumpliendo unos requisitos mínimos ${ }^{114}$. La Ley recoge esta posibilidad como una excepción, pero la

funciones de asesoramiento y control preventivo específicas y propias del puesto de trabajo al que accedió".

111 En honor al autor de la novela El Gatopardo, Giuseppe Tomasi di Lampedusa. Este autor hacía expresas a uno de sus personajes esa cínica idea de que el cambio era necesario para que todo siguiera igual. Como apunta Jiménez: "Después de muchos escándalos hemos asistido a una sucesión de cambios legales con los que dar la apariencia de que se reaccionaba ante la crisis abierta por las revelaciones sin que en realidad hubiera la más mínima intención de ir a las raíces de las verdaderas causas del problema", vid. JIMÉNEZ SÁNCHEZ, Fernando, "Las hojas y el rábano: tres errores en el combate de la corrupción”, Claves de Razón Práctica, no 246 (2016), pp. 9-21, pp. 14 y 15.

112 Véase la noticia aparecida al respecto en La Opinión de Málaga, publicada el 11 de junio de 2015, con el titular "Hay muchos interventores y secretarios con depresión por las presiones de los alcaldes", en el que el presidente del Colegio de Secretarios, Interventores y Tesoreros de la Administración Local de Málaga declaraba: "Como pasa en Ayuntamientos importantes no quieren a los interventores y les asignan retribuciones muy bajas para que no vayan habilitados, aunque por ley debería de haberlos. Si uno mira los interventores que están en grandes municipios, el 99, $9 \%$, por no decir el $100 \%$, son puestos por libre designación”. http://www.laopiniondemalaga.es/malaga/2015/06/11/hay-interventoressecretarios-depresion-presiones/772790.html (Último acceso: 25/11/2016)

${ }^{113}$ En el Ayuntamiento de Murcia se abrió un concurso aparentemente por méritos para proveer la plaza de interventor, pero se reservaba la posibilidad de descartar a los candidatos en último término. Así ocurrió en 2014, cuando el Partido Popular desechó la candidatura de Fernando Urruticoechea, en la actualidad interventor del Ayuntamiento de Orihuela, al considerarlo "no idóneo" sobre la base de informes redactados por técnicos municipales de Cartagena. Urruticoechea era el único aspirante y cumplía las bases del concurso. Ello explica que, en la Comunidad de Murcia, a fecha de 5 de mayo de 2016, hubiera 35 ayuntamientos investigados de un total de 45 y de ahí que estuvieran vacantes los puestos de interventor de 32 de sus 45 ayuntamientos.

114 Incluso es habitual que ni siquiera ejerzan estas funciones los propios interventores habilitados con carácter nacional, sino que en la mayoría de casos de corrupción municipal, las funciones reservadas no eran realizadas por estos empleados públicos, sino por otros nombrados de manera accidental, que, sin embargo, los medios de comunicación distorsionan al catalogarlos como interventores. Uno de los ejemplos, el caso de corrupción en El Ejido (Almería) conocido como la Operación Poniente: "65 procesados por corrupción en la Operación Poniente, entre ellos el ex alcalde de El Ejido y el ex 
GUTIERREZ, Elena. “Corrupción pública: concepto y mediciones. Hacia el Public compliance como herramienta de prevención de riesgos penales".

realidad es que la excepción se ha convertido en la tónica general ${ }^{115}$. Es más, esta opción está tan normalizada que es habitual que tras las elecciones el partido político al frente del consistorio cese al interventor que nombró el anterior alcalde de otro color político $^{116}$. Las funciones del cuerpo de interventores están tan desactivadas ${ }^{117}$ que un informe negativo o un reparo no tienen ninguna repercusión ${ }^{118}$, como muestra el ejemplo del alcalde de una ciudad andaluza que sólo fue imputado por prevaricación cuando había desatendido 400 reparos ${ }^{119}$.

En línea con otras instituciones europeas sería interesante incorporar el sistema de rotación (cada cinco años) en los funcionarios con altas responsabilidades para evitar perpetuaciones que aboquen a una fiscalización sesgada ${ }^{120}$. La institución de cumplimiento dentro de los entes locales no podría quedar reducida a una única figura,

interventor".

Disponible

en:

http://www.elmundo.es/andalucia/2016/06/20/576832ca46163f7a188b4581.html

Último acceso: 28/11/2016.

${ }^{115}$ Fue la disposición adicional 8. a de la Ley 31/1991, de 30 de diciembre, de Presupuestos Generales del Estado para 1992, la que inició la provisión mediante libre designación para determinados puestos reservados a los anteriormente denominados Cuerpos Nacionales de Administración Local, entre los habilitados con nivel 30 de complemento de destino, posteriormente confirmada por la Ley 10/1993, de 21 de abril, de forma que los puestos de Secretario, Interventor o Tesorero de las diputaciones provinciales, cabildos y consejos insulares, o los de ayuntamientos capitales de comunidad autónoma o de provincia y de municipios con población superior a 75000 habitantes, podían excepcionalmente cubrir estos puestos entre funcionarios habilitados mediante libre designación.

${ }^{116}$ Recientemente, ha vuelto a generar controversia el cese de la Interventora General del Ayuntamiento de Madrid: La Delegación de Gobierno recurre el cese de la interventora del Ayuntamiento de Madrid, El mundo, 3 de octubre, 2016.http://www.elmundo.es/madrid/2016/10/03/57f22e40468aeb85148b458a.html Último acceso: 18/11/2016.

117 Resalta QUERALT JIMÉNEZ como “en la prevención de la corrupción en el ámbito local probablemente lo más urgente no sea acudir a innovadoras recetas sino quizá un mero retorno a las prácticas de control ya conocidas, pero víctimas de una progresiva desactivación, como es, por ejemplo, la intervención, financiera, contable y de racionalidad". Véase, "Reflexiones marginales sobre la corrupción”, en Revista Crítica Penal y Poder, n² (2012), pp. 18-35, p. 27.

${ }^{118}$ La supresión de la capacidad de los alcaldes y consistorios en la fijación del complemento específico de los puestos de trabajo, potestad disciplinaria e influencia en las demás condiciones de trabajo de los funcionarios de los Cuerpos Nacionales de Interventores, Secretarios y Tesoreros de la Administración Local fue una de las 25 medidas de lucha judicial contra la corrupción y la delincuencia económica que apuntó la APIF (Asociación Profesional e Independiente de Fiscales).

119 DOPICO GÓMEZ-ALLER, J.: "Aproximación a las necesidades de reforma legal en relación con la respuesta penal a la corrupción política», cit., nota n 57, pp. 280 y 281; QUERALT JIMÉNEZ propone que ante la existencia de un informe no favorable o negativo de interventores o de secretarios municipales, el expediente administrativo en cuestión se paralice hasta que resulte conforme. Vid., "Diez acciones inmediatas contra la corrupción”, cit. nota nº 67, p. 98.

${ }^{120}$ A la dependencia jerárquica de algunos "controladores» se añade la estructura municipal, que sigue un sistema de strong-major. Esta estructura fundamentada en un strong-major y sus relaciones con la corrupción ha sido estudiada por el Instituto de Buen Gobierno de la Universidad de Gotemburgo, llegándose a concluir que existía una relevante coincidencia entre la existencia de esta modalidad de alcalde y la corrupción en el ámbito local. Esta correlación negativa ha provocado que algunos países viren hacia otros modelos de corporación local como el de council manager (Noruega, Irlanda, Australia) o commitee leader (Suecia, Dinamarca o Finlandia) o gestor profesional. En estas formas de gobierno, los cargos electos poseen la capacidad legislativa, sin embargo, el poder ejecutivo dispone de un directivo profesional nombrado por una mayoría cualificada de concejales y por un periodo de tiempo no coincidente con la elecciones. No menos llamativo es que Francia, España y Portugal mantienen el sistema de strong-major y poseen los peores índices de gobierno a nivel local. Al respecto, LAPUENTE, Vicente, La corrupción en España. Un paseo por el lado oscuro de la democracia y el gobierno, Madrid: Alianza, 2016, p. 45 y ss. 
Polít. crim. Vol. 13, № 25 (Julio 2018) Art. 3, pp. 104-143.

[http://www.politicacriminal.cl/Vol_13/n_25/Vol13N25A3.pdf]

sino que sería conveniente la existencia de una estructura bicéfala que podría ser combinada con el secretario de la corporación ${ }^{121}$. Precisamente, en la legislación italiana se contiene una previsión acerca de los responsables anticorrupción que deben existir en cada administración pública. En el caso de la administración central es el responsable político de cada entidad quien nombra al responsable entre funcionarios de carrera de primer nivel $^{122}$.

No obstante, esta propuesta sería factible en supuestos de corporaciones locales con unas dimensiones reducidas, pero se debería considerar la incorporación de un verdadero cuerpo o unidad de Public compliance en Administraciones más voluminosas. Se estaría ante la figura del public compliance officer con unas funciones ejecutivas y de desarrollo. Algún autor ya ha designado las funciones que debería asumir este órgano: i. Evaluación de las conductas desplegadas por los miembros del ente; ii. Diseñar e implementar un código de cumplimiento, en el que se establezca que se puede y no hacer en materia de integridad; iii. La recepción de denuncias por parte de los empleados públicos; iv. Labores de sensibilización frente a la corrupción ${ }^{123}$.

Si bien es cierto que en determinados espacios cabría preguntarse si no sería suficiente, más que acudir a vías aparentemente innovadoras, reforzar precisamente competencias debilitadas. Sería algo tan sencillo como retornar hacia un fortalecimiento de las figuras de control clásicas como los interventores en las corporaciones locales. Las viejas soluciones a los nuevos problemas, en ocasiones, son las más efectivas.

\subsubsection{La protección de los denunciantes de corrupción en España}

Si se hace un repaso a los supuestos más mediáticos de las tramas de corrupción aparecidas en España, existe en todos ellos un patrón común: denunciar la corrupción no es rentable o, mejor aún, el coste de efectuarlo es muy elevado. No se trata de casos aislados: el que denuncia está renunciando a su futuro profesional ${ }^{124}$. Una de las demandas más reiteradas de Transparencia Internacional a España se centra en la necesidad de legislar en torno a la protección de los denunciantes de fraude o

\footnotetext{
121 Aunque es cierto que en la gran mayoría de ayuntamientos de población reducida el secretario y el interventor se refunden en una única figura.

122 Sobre un análisis completo de la Legge Anticorruzione n.190/2012, vid. NIETO MARTÍN, "De la ética pública al public compliance: sobre la prevención de la corrupción en las administraciones públicas”, cit. nota n 22, p. 34 .

123 Sobre esta figura de nuevo cuño, vid. QUERALT JIMÉNEZ, "Public Compliance y corrupción: Análisis conceptual y propuestas", cit. nota nº, p.6.

${ }^{124}$ Los casos son numerosos. Le ocurrió a Ana Garrido, quien abrió la veda del Caso Gürtel. Perdió su anonimato, su puesto de trabajo, fue acosada laboralmente en el ayuntamiento de Boadilla y está imputada por un delito de infidelidad en la custodia de documentos y violación de secretos. Éste quizás es el caso más mediático, al aparecer en prensa con asiduidad, pero no el único. Itziar González, tras testificar en el Caso Millet, está pendiente de juicio desde hace más de 3 años por amenazas y robo de documentos en su domicilio. La interventora del Ayuntamiento de Santa Coloma de Gramanet, Maite Carol, denunció presiones del alcalde implicado en el Caso Pretoria y fue cesada precisamente por presentar informes que advertían de las ilegalidades cometidas por el Ayuntamiento con empresas privadas. En referencia a este fenómeno, "Acosados por denunciar casos de corrupción: historias de 'funcionarios coraje'“،, aparecida en El Plural el 25 de septiembre de 2015. Disponible en: http://www.elplural.com/2015/09/25/acosados-por-denunciar-casos-de-corrupcion-historias-defuncionarios-coraje (Último acceso: 20/04/2017).
} 
GUTIERREZ, Elena. “Corrupción pública: concepto y mediciones. Hacia el Public compliance como herramienta de prevención de riesgos penales".

corrupción $^{125}$. Pese a que algunas de las disposiciones relativas a la creación de agencias antifraude poseen referencias a la protección del denunciante ${ }^{126}$, la única disposición que aborda únicamente esta cuestión en materia de empleados públicos es la Ley 2/2016, de 11 de noviembre, por la que se regulan las actuaciones para dar curso a las informaciones que reciba la Administración Autonómica sobre hechos relacionados con delitos contra la Administración Pública y se establecen las garantías de los informantes de la Comunidad de Castilla y León ${ }^{127}$. Se trata de una normativa especialmente escueta, pero no por ello exenta de controversia, que consta de tres artículos, dos disposiciones adicionales y tres disposiciones finales.

El objeto de la Ley es regular las actuaciones de la Administración de la Comunidad de Castilla y León ante las informaciones que le sean facilitadas por su personal respecto de actuaciones que hayan sido realizadas por altos cargos o personal de la Administración General e Institucional en el ejercicio de sus funciones de las que pudiera derivarse un posible delito contra la Administración Pública de los regulados en el Título XIX del Código Penal, así como establecer las garantías que se otorgan a los informantes. Sin embargo, el primer aspecto negativo de la Ley es que la información se ha de remitir a la Inspección General de Servicios, cuya independencia es cuestionable, ya que se trata de un ente que depende jerárquica y funcionalmente de la Consejería de presidencia de la Junta de Castilla y León, cuyo máximo responsable es nombrado mediante libre designación. En cuanto a las garantías de protección del empleado público denunciante, se establece que "no podrá ser removido de su puesto de trabajo,

\footnotetext{
${ }^{125}$ Se trata de una de las diez recomendaciones efectuadas por Transparencia Internacional a los partidos políticos españoles. Las diez medidas propuestas son las siguientes: 1) Promover la despolitización de los órganos constitucionales y disminuir de forma significativa el excesivo y desequilibrado poder de los Partidos políticos en relación con la sociedad y los ciudadanos; 2) Reducción del número de aforados (ningún país en Europa tiene tantos aforados como España), así como las características del aforamiento, limitándolo exclusivamente a las actividades y actuaciones relacionadas con el correspondiente cargo público; 3) Eliminación de la posibilidad de conceder indultos por corrupción; 4) Disminución sensible del clientelismo político, disminuyéndose a tal efecto la enorme cantidad de cargos de libre designación existentes en este país; 5) Mejorar diversas disposiciones legales en el ámbito sancionador, incluyéndose a tal efecto la figura del delito por enriquecimiento ilícito, así como el desarrollo de un régimen específico de infracciones y sanciones en la Ley de Transparencia; 6) Aprobación urgente del Reglamento de la Ley de Transparencia, todavía pendiente tres años después de haberse publicado la Ley; 7) Publicación de una Ley de protección a los denunciantes: Para que los ciudadanos se sientan protegidos legalmente cuando conozcan hechos y deseen formular denuncias por fraude y corrupción; 8) Regulación de los Lobbies: Es necesario que se regulen desde un punto de vista legal los lobbies, se propicie su transparencia social, y se establezca obligatoriamente la creación de Registros de grupos de interés en las distintas instituciones públicas y parlamentarias; 9) Transparencia de las formaciones políticas: Es necesario que aumente la transparencia financiera de los Partidos y de las entidades perimétricas de los mismos (Fundaciones, etc.), siguiendo de esta forma las recomendaciones del GRECO; 10) Educación: Los Partidos políticos y grupos parlamentarios han de fomentar medidas para que en los distintos niveles educativos se introduzcan conceptos y materias relacionados con la ética, los valores, la transparencia, la integridad y la prevención de la corrupción.

${ }^{126}$ Ley 14/2008, de 5 de noviembre, de la Oficina Antifraude de Cataluña y, más en profundidad, la Ley 11/2016, de 28 de noviembre, de la Agencia de Prevención y Lucha contra el Fraude y la Corrupción de la Comunitat Valenciana y Ley 16/2016, de 9 de diciembre, de creación de la Oficina de Prevención y Lucha contra la Corrupción en las Illes Balears.

127 Si bien a la fecha de cierre de este artículo (20/06/2017) se encuentra en fase de tramitación parlamentaria la Proposición de Ley Integral de Lucha contra la Corrupción y Protección de los Denunciantes, cuyo objetivo, entre otros, de acuerdo con la Exposición de Motivos, es "contar con mejores controles con el fin de limitar la discrecionalidad de los políticos y los altos cargos para efectuar nombramientos y contrataciones en el sector público" y "fomentar la denuncia de la corrupción" entre funcionarios y trabajadores de la Administración pública.
} 
Polít. crim. Vol. 13, № 25 (Julio 2018) Art. 3, pp. 104-143.

[http://www.politicacriminal.cl/Vol_13/n_25/Vol13N25A3.pdf]

cualquiera que sea su forma de provisión". La normativa, pese a tener vocación de garantizar la protección de los denunciantes, no contempla ninguna clase de asesoramiento legal para éstos. Llama especialmente la atención que se recalquen las represalias a los denunciantes cuando no se pruebe la veracidad de sus informaciones ${ }^{128}$.

La Ley 11/2016, de 28 de noviembre, de la Agencia de Prevención y Lucha contra el Fraude y la Corrupción de la Comunidad Valenciana contiene en su art. 14 un estatuto de la persona denunciante. Se considera persona denunciante, a efectos de esta ley, a cualquier persona física o jurídica que comunique hechos que puedan dar lugar a la exigencia de responsabilidades legales. Una de las garantías que incluye esta normativa es la provisión a los denunciantes de inmediata asesoría legal para los hechos relacionados con la denuncia, con la correspondiente confidencialidad de la identidad. Este asesoramiento se extiende a los procedimientos que se hayan podido interponer contra su persona con motivo de la denuncia. Asimismo, se establece que la agencia velará para que estas personas no sufran durante la investigación ni después de ella «ningún tipo de aislamiento, persecución o empeoramiento de las condiciones laborales o profesionales, ni ningún tipo de medida que implique cualquier forma de perjuicio o discriminación»y, para ello, a instancia de la persona denunciante:

\begin{abstract}
"La agencia podrá instar al órgano competente a trasladarla a otro puesto, siempre que no implique perjuicio a su estatuto personal y carrera profesional $\mathrm{y}$, excepcionalmente, podrá también instar al órgano competente a conceder permiso por un tiempo determinado con mantenimiento de la retribución". ${ }^{29}$
\end{abstract}

Esta protección podrá mantenerse, mediante una resolución de la agencia, incluso más allá de la finalización de los procesos de investigación que desarrolle. Una novedad que introduce esta normativa es la futura creación de una oficina virtual del empleado público, que permita a este colectivo "señalar de forma confidencial los expedientes administrativos que juzguen irregulares". Por último, sería conveniente que la protección del denunciante por casos derivados de corrupción se legislara a nivel nacional ${ }^{130}$ y se desarrollara posteriormente por las Comunidades Autónomas.

2.2.4 El control externo: El Tribunal de Cuentas y los OCEX como órganos de monitorización periódica y auditoría externa

\footnotetext{
${ }^{128}$ En el apartado 5 del art. 3 se señala que "se considerará falta grave la presentación de informaciones infundadas cuando en las actuaciones llevadas a cabo en la información reservada se pruebe de forma manifiesta su falta de fundamento, todo ello sin perjuicio de las consecuencias que establece el ordenamiento jurídico para los supuestos de acusación y denuncia falsas y simulación de delitos tipificados en el Capítulo V, del Título XX del Libro II del Código Penal".

La Plataforma en Defensa de lo Público ha catalogado esta Ley como de "desprotección al funcionario público". http://cadenaser.com/emisora/2016/11/05/radio_valladolid/1478338646_373098.html (Último acceso: 20/01/2017).

${ }^{129}$ Art. 14 d) de la Ley 11/2016, de 28 de noviembre, de la Agencia de Prevención y Lucha contra el Fraude y la Corrupción de la Comunidad Valenciana.

${ }^{130}$ El Parlamento de Cantabria ha instado al Gobierno a impulsar una ley nacional, comprometiéndose a adaptar la reglamentación autonómica en los seis meses siguientes a su tramitación. Véase, "Las Autonomías regulan la protección de los denunciantes de corrupción", Diario El País, 07/01/2017. A la fecha de la elaboración de este trabajo, Aragón, Navarra y Asturias han iniciado los trabajos para aprobar leyes o unidades anticorrupción que incluyen medidas de protección a los denunciantes.
} 
GUTIERREZ, Elena. “Corrupción pública: concepto y mediciones. Hacia el Public compliance como herramienta de prevención de riesgos penales".

No es el propósito del presente trabajo realizar una propuesta exhaustiva de una futura (e inaplazable para algunos) reforma del Tribunal de Cuentas ${ }^{131}$, si bien sí me centraré en destacar alguna de las cuestiones que muestran la ineficiencia de este órgano para hacer frente al fenómeno de la corrupción. Tomaré como referencia el informe realizado por la Fundación Hay Derecho "Análisis del funcionamiento del Tribunal de Cuentas. Comparativa europea y la evaluación externa al Tribunal de Cuentas mediante sistema peer review por el Tribunal de Cuentas Europeo y el Tribunal de Cuentas portugués". Los motivos de esta primera auditoría externa a la que se somete esta institución tienen su origen en los escándalos destapados en prensa acerca del nepotismo en los cargos y las corruptelas en los contratos que obligaron a la institución a dotar de más transparencia a sus funciones ${ }^{132}$.

Conviene antes trazar de forma sintética cómo se articula el control externo en España para poder extraer mayores conclusiones. La gestión económica del sector público se controla desde una naturaleza bifronte. Por un lado, se encuentra el Tribunal de Cuentas, órgano supremo de fiscalización de las cuentas y de la gestión económica del Estado y, por otro lado, se hallan los órganos de control externo de las Comunidades Autónomas (en adelante, OCEX), aunque no todas ellas poseen un órgano de fiscalización externa $^{133}$. Estos organismos actúan en concurrencia funcional con el Tribunal de Cuentas, si bien su coordinación como puntualizan algunos autores es sumamente mejorable ${ }^{134}$. La competencia para su creación corresponde a los distintos Parlamentos autonómicos, que regulan su estatuto, funciones y competencias, por norma con rango de Ley. Los OCEX ejercen funciones de fiscalización, pero no de enjuiciamiento, y su competencia se extiende a la Administración autonómica y local de su ámbito territorial. $\mathrm{Su}$ propia existencia fue cuestionada en el año 2013 con una desconcertante propuesta dentro del informe para la reforma de las Administraciones Públicas del Consejo de Ministros que pretendía su desaparición y la integración en secciones territoriales del Tribunal de Cuentas. No obstante, esta propuesta no prosperó y fue enérgicamente criticada.

El primer aspecto reseñable es que se trata de una institución "fosilizada", ya que su concepción de control se limita en mayor medida a una contabilidad presupuestaria. No se ha atendido a marcos metodológicos homologables con estándares internacionales ${ }^{135}$. Es más, no hay un seguimiento detallado y sistemático del cumplimiento de las

\footnotetext{
${ }^{131}$ Sobre la necesidad de reforma del Tribunal de Cuentas, ONRUBIA FERNÁNDEZ, Jorge, "La lucha contra la corrupción en el sector público: fiscalización, intervención y control económico-financiero", Public Compliance ..., cit. nota n ${ }^{\circ}$ 19, pp. 221-150, p. 247; PEÑA OCHOA, Alfonso, "El nuevo rol de los organismos de control externo frente a la corrupción", cit., nota n²0, pp. 83-108, p. 91.

132 "Los lazos de parentesco en el Tribunal de Cuentas alcanzan a 100 empleados", Diario El País, 23 de junio de 2014.2 Disponible en: http://politica.elpais.com/politica/2014/06/23/actualidad/1403548994_107851.html (Último acceso: 29/11/2016).

${ }^{133}$ La LO 2/1982, de 12 de mayo, del Tribunal de Cuentas, señala en su artículo 1.2 que el Tribunal de Cuentas "es único en su orden y extiende su jurisdicción a todo el territorio nacional, sin perjuicio de los órganos fiscalizadores de cuentas que para las Comunidades Autónomas puedan prever sus Estatutos".

${ }^{134}$ PEÑA OCHOA, "El nuevo rol de los organismos de control externo frente a la corrupción", cit., nota $\mathrm{n}^{\circ} 20$, p. 85 .

${ }^{135}$ El mismo sistema arcaico cabe predicar de la Intervención General del Estado, como órgano de control interno, tal y como resalta la Circular 1/2009 de la IGAE, encargada de desarrollar aspectos técnicos del control financiero permanente, que otorga a la auditoría un papel residual, vinculado como técnica principalmente a la documentación y archivo de trabajados de control.
} 
recomendaciones que realiza. En el año 2014 únicamente uno de los 55 informes de auditoría realizados fue de seguimiento ${ }^{136}$. Asimismo, en cuanto a datos cuantitativos del funcionamiento, el programa anual de fiscalización 2014 incluía que el Tribunal de Cuentas debía elaborar un total de 119 fiscalizaciones ${ }^{137}$, pero sólo se han llevado a cabo 55. Este dato contrasta con su homólogo francés, la Cour des Comptes, cuyo programa anual de fiscalización no es público, no teniendo información al respecto ni el Parlamento. El objetivo es lograr independencia y lo más relevante, que las entidades que van a ser fiscalizadas no se preparen para recibir la auditoría.

El informe peer review pone de relieve, de nuevo, como el sistema de libre designación ${ }^{138}$, anteriormente mencionado para el sistema de provisión de puestos de interventores en los ayuntamientos, es el más empleado para cubrir los puestos de directivos del Tribunal, aparte de señalar que crea un clima de conflicto y tensión entre el personal ${ }^{139}$. Precisamente de un estudio comparativo entre los órganos fiscalizadores de control en el marco europeo se puede apreciar el desequilibrio existente entre el personal directivo y el personal técnico en el Tribunal de Cuentas español, ya que en España hay 4,4 trabajadores por cada directivo, mientras que en el Reino Unido y el Tribunal de Cuentas Europeo hay 12,5 y 13 respectivamente ${ }^{140}$.

Para la asunción de un Public compliance es necesario que el Tribunal de Cuentas reconfigure su estructura y, en especial, el modo de fiscalización. Pese a que una corriente mayoritaria dentro del Tribunal de Cuentas ha cuestionado que la lucha contra el fraude y la corrupción sea una de sus finalidades prioritarias ${ }^{141}$, ya se ha podido apreciar un cambio de enfoque en el Consejo de Cuentas de Galicia, al que la Ley $8 / 2015$, de 7 de agosto, ha otorgado funciones en materia de prevención y control de la corrupción. Esta nueva normativa me parece un avance porque da carta de naturaleza a la sección de prevención de la corrupción en el sector público gallego, se contempla también que los procedimientos de fiscalización se inicien tras denuncias de particulares y, además, incluye competencias como la colaboración con las administraciones sujetas a su ámbito de actuación para elaborar manuales de gestión de riesgos, comprobar los sistemas de prevención de la corrupción que se instalen y asesorar sobre los

\footnotetext{
$136 \mathrm{Si}$ bien algunos informes de fiscalización incluyen un apartado dedicado al seguimiento de recomendaciones previas del Tribunal. Así lo indica el peer review al que se sometió en 2015 el Tribunal de Cuentas.

${ }^{137}$ En Italia, durante 2014 la sección central de la Corte llevó a cabo 244 actos de naturaleza fiscalizadora (informes, resoluciones, etc.), y las secciones regionales realizaron 5.067 actividades de forma colegiada, incluyendo deliberaciones, opiniones y decisiones sobre las cuentas de los entes locales, y han examinado la legitimidad de 13.639 actos. Para un estudio comparativo completo, interesante Informe de la Fundación "Hay Derecho": "Análisis del funcionamiento del Tribunal de Cuentas. Comparativa Europea”, presentado el 2 de octubre de 2015 en la sede del Parlamento Europeo en España.

${ }^{138}$ Además, existe un Interventor encargado de las funciones de auditoria interna que depende del Pleno, por el que es nombrado y cesado libremente.

139 En especial en las relaciones existentes entre los funcionarios de cuerpos propios del Tribunal de Cuentas y los funcionarios llegados desde otras instituciones.

${ }^{140}$ Véase esta cuestión en el Informe de la Fundación Hay Derecho "Análisis del funcionamiento del Tribunal de Cuentas. Comparativa Europea", p. 48.

141 Véase PEÑA OCHOA, "El nuevo rol de los organismos de control externo frente a la corrupción", cit., nota $\mathrm{n}^{\circ} 20$, p. 91. Sobre la función de los OCEX, en el XI encuentro técnico de los OCEX celebrado en Oviedo en junio de 2015, entre sus conclusiones, se apunta que "no son los OCEX los que tienen que perseguir el fraude y la corrupción, pervirtiendo de ese modo su función principal. Por supuesto, sí están obligados a colaborar con otras instancias administrativas y judiciales. Como en una carrera de relevos, los OCEX entregan el testigo cuando termina la fiscalización”.
} 
GUTIERREZ, Elena. “Corrupción pública: concepto y mediciones. Hacia el Public compliance como herramienta de prevención de riesgos penales".

instrumentos normativos en relación a la prevención de la corrupción. El Consejo de cuentas gallego ya ha aprobado un primer programa de actividades de prevención de la corrupción dentro del plan de trabajo para el ejercicio de 2017. Conviene destacar que la evaluación de los sistemas de prevención del sector público gallego se pretende realizar a través de las siguientes acciones: i. Elaboración y aprobación de directrices técnicas para el análisis de la situación de los sistemas de control interno de las entidades integrantes del sector público autonómico; ii. Realización de una evaluación del control interno de manera diferenciada para el subsector Administración general, subsector de la Administración institucional y subsector administración local, en base a cuestionarios sobre la situación de los sistemas de control interno de las distintas entidades de esos sectores; iii. Diagnóstico de la situación de los sistemas de control interno de las entidades integrantes del sector público autonómico y planteamiento de recomendaciones por parte de la Sección de Prevención de la Corrupción del Consello de Contas a las distintas entidades sobre la necesidad de implantación de sistemas de prevención de riesgos de corrupción; iv. Elaboración y aprobación de herramientas metodológicas para la implementación de sistemas de prevención de riesgos de corrupción, singularmente guías técnicas para su evaluación y modelos tipo de planes de prevención.

A mi modo de ver, el Tribunal de Cuentas y los correspondientes OCEX deben contribuir al estadio previo de prevención y detección de la corrupción que requiere todo Public Compliance, ya que, en la línea de Fernández Ajenjo, la creación de unidades especializadas en auditoría forense (como una unidad de fiscalización antifraude) en las instituciones de control nos acerca al buen funcionamiento del modelo americano acorde con una

"propuesta paulatina y cada vez más especializada de la responsabilidad de lucha contra la corrupción por los diferentes órganos de control, en el que a la $\mathrm{GAO}^{142} \mathrm{le}$ ha correspondido la coordinación y, en su caso, investigación de los asuntos relacionados con la gestión de fondos públicos, para lo cual cuenta con un órgano ad hoc, fortalecido y renovado, como la Forensic Audits and Specials Investigations"143.

En contra de este planteamiento, Villoria y Peña, consideran que es más eficiente investigar la corrupción en órganos especializados expresamente creados, como la OLAF $^{144}$ o las agencias antifraude, sin perjuicio de que en determinados supuestos cuenten con la asistencia de los órganos de control ${ }^{145}$.

\subsubsection{Las agencias antifraude: La oficina antifraude de Cataluña como experiencia}

Antes de que los escándalos de corrupción pública en España acapararan cada informativo y la denominada ética pública y las agencias antifraude empezaran a

142 Oficina de Rendición de Cuentas del Gobierno de los Estados Unidos (Government Accountabiliy Office).

${ }^{143}$ FERNÁNDEZ ASENJO, José Antonio, “El control de las Administraciones Públicas y la lucha contra la corrupción", Cizur Menor: Civitas, 2011, p. 468.

144 Oficina Europea de Lucha contra el Fraude.

145 VILLORIA MENDIETA, Manuel, "El buen gobierno y la lucha contra la corrupción en las instituciones públicas", en PALOMAR OLMEDA, Alberto y GARCÉS SANAGUSTÍN, La gestión de los fondos públicos: control y responsabilidades: Los derechos de los ciudadanos, las garantías y las vías de actuación para su efectividad, Cizur Menor: Aranzadi, 2013, pp. 123-156. 
Polít. crim. Vol. 13, № 25 (Julio 2018) Art. 3, pp. 104-143.

[http://www.politicacriminal.cl/Vol_13/n_25/Vol13N25A3.pdf]

convertirse en una propuesta frente a la corrupción, en Cataluña, se puso en funcionamiento en el último trimestre de 2009 la Oficina Antifraude de Cataluña (en adelante, OAC) ${ }^{146}$. Esta aportación pionera en el seno de la Administración pública tuvo su origen en la corrupción producida en las adjudicaciones de obra pública ${ }^{147}$. Con su puesta en funcionamiento, España cumplía por primera vez con lo establecido en el artículo 6 de la Convención de las Naciones Unidas contra la corrupción ${ }^{148}$ al crear un órgano especializado e "independiente" encargado de prevenir la corrupción ${ }^{149}$. Posteriormente, han empezado a proliferar más oficinas, creándose la Oficina Antifraude del Ayuntamiento de Madrid, la Oficina para la Transparencia y las Buenas Prácticas del Ayuntamiento de Barcelona, la Agencia de Prevención y Lucha contra el Fraude y la corrupción de la Comunidad Valenciana y la Oficina de Prevención y Lucha contra la Corrupción de la Islas Baleares ${ }^{150}$.

El periodo de actividad de la Oficina Antifraude de Cataluña (2009-2016) permite extraer datos de relevancia para construir el modelo de Public Compliance que podría ser más efectivo. La actividad da buena muestra de las posibilidades que puede aportar una institución de estas características. En 2015, la Oficina Antifraude recibió y tramitó un total de 153 denuncias, el 64 por ciento sobre asuntos municipales, el 18 sobre la Administración autonómica, el 3 por ciento sobre Consejos comarcales, un 1 por ciento en lo que respecta a las Diputaciones, otro 1 por ciento sobre fundaciones, un 10 por ciento sobre entes semipúblicos y un 3 por ciento sobre otros entes y administraciones. En cuanto a las materias objeto de investigación en las actuaciones concluidas por este organismo en 2015 destacan que el 38 por ciento estuvieran conectadas con la contratación administrativa y el 26 por ciento con la función pública. La memoria de 2015 de la OAC también aporta unos interesantes datos acerca de la tipología de los denunciantes. El 59 por ciento de las comunicaciones presentadas fueron interpuestas por particulares, el 21 por ciento por grupos políticos ${ }^{151}$, el 7 por ciento por funcionarios o trabajadores públicos y el 7 por ciento por sindicatos. Resulta especialmente llamativo que del total de denuncias tan sólo el 22 por ciento de los denunciantes solicitaron reserva de identidad. La OAC no únicamente sirve de canalizador de denuncias que tras investigar puedan dar fruto a una investigación penal en la Fiscalía, sino que realiza una gran labor a través de estudios ${ }^{152}$, barómetros ${ }^{153}$ y recomendaciones de mejora a los diversos organismos. Constituye una potente herramienta formativa y de sensibilización para la Administración pública, mediante la organización de cursos relacionados con la buena gestión, códigos de conducta y prevención de la corrupción. La OAC permite

\footnotetext{
146 Creada por la Ley 14/2008, de 5 de noviembre, de la Oficina Antifraude de Cataluña.

147 Conocida es la interpelación del entonces presidente de la Generalitat al jefe de la oposición cuando señalaba que su problema era "el tres por ciento", refiriéndose a las comisiones ilegales en la adjudicación de obras públicas.

148 Aprobada en Nueva York el 31 de octubre de 2003 y ratificada por España en 2006.

${ }^{149}$ En el contexto europeo, ya existían la Oficina Antifraude Europea (OLAF) creada por la decisión de la Comisión de 28 de abril de 1999 y, entre otras, la Autorità Nazionale Anticorruzione en Italia (ANAC).

${ }^{150}$ Tras 109 enmiendas a lo largo de su tramitación parlamentaria se aprobó la Ley el 11 de noviembre de 2016.

151 Un dato que podría interpretarse como "denuncias" como arma arrojadiza contra otros partidos políticos.

${ }^{152}$ Informe de la OAC sobre gestión de los conflictos de interés: http://www.antifrau.cat/images/web/docs/publicacions/estudis_integricat/20160526-conflicte-interes.pdf

${ }^{153}$ El barómetro 2014 de la OAC recoge las percepciones y actitudes de la ciudadanía alrededor del fenómeno de la corrupción en Cataluña.
} 
GUTIERREZ, Elena. “Corrupción pública: concepto y mediciones. Hacia el Public compliance como herramienta de prevención de riesgos penales".

cubrir una laguna muy necesaria: la carencia de datos empíricos que permitan estudiar el fenómeno de la corrupción en la Administración pública con perspectiva.

\section{Un apunte final: La administración pública como responsable penal}

La doble velocidad que se ha aducido en la implementación de las medidas de compliance con respecto a las corporaciones privadas y las Administraciones públicas radica en un incentivo claro que poseen las primeras: la posibilidad de exonerarse de responsabilidad penal. Sin embargo, no se ha mencionado que el Código Penal español contiene una responsabilidad penal para Administraciones públicas, aunque muy acotada, que abre, a su vez, relevantes cuestiones a considerar.

En 2012, la reforma del art. 31 bis que llevó a cabo la LO 7/2012, de 27 de diciembre, que reformó el Código Penal en materia de transparencia y lucha contra el fraude fiscal y en la Seguridad Social, y fue aprovechada en su tramitación parlamentaria para suprimir del listado de sujetos excluidos a los partidos políticos y a los sindicatos, no incluyó a las denominadas "sociedades mercantiles estatales que ejecuten políticas públicas o presten servicios de interés económico general", que se mantuvieron en el catálogo de personas jurídicas exentas de responsabilidad penal (art. 31 bis 5). Esta previsión fue especialmente objeto de críticas por la OCDE que mostró su preocupación por la elusión del régimen de responsabilidad penal, a la vista de la titularidad pública de las acciones de las entidades financieras rescatadas por el Estado a través del FROB ${ }^{154}$, resaltando que "en España, la exclusión de la responsabilidad penal de estas sociedades es aún más preocupante por el hecho de que en muchos casos están controladas por gobiernos regionales" y, por lo tanto, recomendaba que las sociedades estatales fueran penalmente responsables del delito del actual art. 286 ter $^{155}$. La exclusión de las sociedades mercantiles estatales planteaba problemas, ya que nada se decía acerca de las "autonómicas" y "locales" que a priori quedaban sujetas al régimen de responsabilidad penal, pues en estos ámbitos también se constituían sociedades mercantiles para ejecutar políticas públicas.

La LO 1/2015, recogiendo las recomendaciones de la OCDE, incluye un nuevo artículo 31 quinquies en el que "las sociedades mercantiles públicas que ejecuten políticas públicas o presten servicios de interés económico general" pueden ser responsables penalmente, si bien limitando sus penas ${ }^{156}$. Con la alusión a las "sociedades mercantiles públicas" y no al apelativo de "estatales", se consideran integradas tanto las constituidas por las Comunidades Autónomas como por las Entidades locales ${ }^{157}$. Las penas de multa

\footnotetext{
${ }^{154}$ Así lo destaca la Circular 1/2016 de la Fiscalía General del Estado, sobre responsabilidad penal de las personas jurídicas conforme a la reforma del Código Penal efectuada por la Ley Orgánica 1/2015.

155 Informe adoptado por el Grupo de Trabajo el 14 de diciembre de 2012 correspondiente a la fase 3 de la evaluación sobre el cumplimiento en España del Convenio contra la Corrupción de Agentes Públicos Extranjeros en las Transacciones Comerciales Internacionales.

${ }^{156}$ La limitación se justifica en el Informe del Consejo de Estado, de 27 de junio de 2013, con la razón de "garantizar la adecuada protección de los intereses públicos y la correcta prestación de los servicios económicos de interés general encomendados a estas sociedades, y que podrían resultar perjudicados en caso de imponerse penas como la suspensión de actividades o la clausura de locales, por ejemplo".

157 Véase, al respecto, DE LA CUESTA ARZAMENDI, José Luis, "Responsabilidad de las personas jurídicas en el Derecho español”, en EL MISMO, Responsabilidad penal de las personas jurídicas, Cizur Menor: Aranzadi, 2013, pp. 49-102, p. 78.
} 
Polít. crim. Vol. 13, № 25 (Julio 2018) Art. 3, pp. 104-143.

[http://www.politicacriminal.cl/Vol_13/n_25/Vol13N25A3.pdf]

y la intervención judicial son las únicas aplicables a estas sociedades, salvo que se trate "de una forma jurídica creada por sus promotores, fundadores, administradores o representantes con el propósito de eludir una eventual responsabilidad penal", en cuyo caso el juez podrá imponer las medidas recogidas en el apartado 7 del art. $33 \mathrm{CP}$. Esta extensión pretende evitar que la forma prime sobre la realidad material y que la huida del Derecho Administrativo no implique una nueva huida del Derecho Penal ${ }^{158}$. Pero frente a esa idea, no se comprende como esta posibilidad no se extiende a todas las personas jurídicas de naturaleza pública, como sí se contemplaba en la redacción anterior, y no sólo alcanza a las sociedades mercantiles públicas. Sin embargo, se trata de una previsión que prácticamente impide la aplicación de las penas distintas a la multa y a la intervención judicial, ya que viene a exigir que la sociedad se haya constituido $\mathrm{ad}$ hoc con el objetivo de eludir la responsabilidad penal, por lo que la ilegalidad sobrevenida de la sociedad no será relevante ${ }^{159}$.

La Circular 1/2016, sobre responsabilidad penal de las personas jurídicas conforme a la reforma del Código Penal efectuada por la Ley Orgánica 1/2015, alerta de que la restricción relativa a que se traten de sociedades mercantiles públicas que ejecuten políticas públicas o presten servicios de interés económico general supone que:

"La ejecución y prestación de tales políticas y servicios se atribuye de ordinario en el ámbito estatal a los organismos autónomos, los consorcios o a las entidades públicas empresariales no resulta infrecuente que las sociedades estatales, especialmente las de capital exclusivo público, presten servicios públicos de interés económico general. Será finalmente el análisis del concreto fin público que desarrolla cada sociedad el que determine la calificación y relevancia del servicio prestado, pues el concepto de servicio público, desde una perspectiva funcional del patrimonio público, no ha de entenderse ligado o encorsetado por categorías administrativas, como interpreta la más reciente jurisprudencia en relación con el subtipo agravado del vigente art. 432.3 a) CP"160.

A la vista de estas observaciones, conviene plantearse si las previsiones contempladas para la responsabilidad penal de las sociedades mercantiles públicas (que ejecuten políticas públicas o presten servicios de interés económico general) son adecuadas ${ }^{161}$. Las singularidades radican en la imposición limitada de las penas que se les pueden imponer. Por un lado, se contempla la pena por antonomasia de las personas jurídicas, la multa, y, por otro lado, la aplicación de la intervención judicial como únicas penas. La aplicación de la multa podría colisionar con la idea de que las consecuencias del delito repercutirían en los propios ciudadanos, pues piénsese en la restricción de recursos

\footnotetext{
${ }^{158}$ En particular, GÓMEZ RIVERO, Carmen, "El castigo penal de la corrupción en el ámbito del llamado sector instrumental", Revista Electrónica de Ciencia Penal y Criminología, nº 18 (2016), pp. 1-36, p. 8.

159 "Esta limitación en principio no producirá lagunas punitivas pues se trata de una conducta difícil de imaginar en los organismos, entidades y organizaciones mencionadas en el núm. 1 del art. 31 quinquies, a salvo, tal vez, algunas entidades públicas empresariales, de naturaleza más próxima a las sociedades mercantiles públicas". Lo advierte la Circular 1/2016 de la Fiscalía General del Estado, sobre responsabilidad penal de las personas jurídicas conforme a la reforma del Código Penal efectuada por la Ley Orgánica 1/2015, p. 35.

${ }^{160} \operatorname{STS~n}^{\circ} 277 / 2015$, de 3 de junio.

${ }^{161}$ Sobre la responsabilidad penal de los administradores de estas sociedades, véase GÓMEZ RIVERO, Carmen: "El castigo penal de la corrupción en el ámbito del llamado sector instrumental", cit. nota n 153 , p. 9 y ss.
} 
GUTIERREZ, Elena. “Corrupción pública: concepto y mediciones. Hacia el Public compliance como herramienta de prevención de riesgos penales".

presupuestarios que sufriría la entidad con motivo de la deuda ${ }^{162}$. Sin embargo, es cierto que esa detracción no dejaría de ser un aspecto que ya se produce en el ámbito de la responsabilidad por el funcionamiento anormal de la Administración pública en el ámbito administrativo. Pese a ello, considero que la multa no es la opción más adecuada para las Administraciones públicas, ya que la lógica imperante en ellas dista mucho de la maximización del beneficio sobre la que se opera en entidades corporativas basada en la teoría de costes-beneficios. El elemento disuasorio de prevención especial no estaría bien formulado ${ }^{163}$. Los socios, en el ámbito privado, consideran a la multa un relevante escollo para la obtención de beneficios, a nivel reputacional, como desventaja competitiva en el sector y con implicaciones en futuras contrataciones tanto privadas como públicas. Por el contrario, en una sociedad mercantil pública, estos componentes que podrían tener sentido, tanto desde la perspectiva de la prevención general como de la especial en una corporación privada, no son predicables de las motivaciones que rigen la estructura pública. Otro aspecto sobre el que conviene llamar la atención es que, a diferencia de los partidos políticos que han de contar con un programa de cumplimiento con carácter preceptivo ${ }^{164}$, en el caso de las sociedades mercantiles públicas no se contiene ninguna previsión específica y, por tanto, este tipo de programas que configurarían un Public compliance sería, como en el resto de las personas jurídicas, facultativo $^{165}$. Interesa apuntar que al estar la responsabilidad penal de las sociedades mercantiles públicas sujeta a las reglas generales del art. 31 bis, los delitos por los que pueden responden se adscriben al sistema numerus clausus y fuera de su órbita se encuentran la gran mayoría de delitos contra la Administración pública ${ }^{166}$.

En la esfera pública, se ha de realizar un especial hincapié en las medidas preventivas que combatan la peligrosidad entendida como la incapacidad para organizarse correctamente. Y, para ello, son las sanciones no pecuniarias las que mayor peso podrían tener. La intervención judicial, sería una vía alternativa que redundaría en mayores beneficios, ya que permitiría una reorganización preventiva de la entidad ${ }^{167}$. Asimismo, la responsabilidad penal de las sociedades mercantiles públicas, de nuevo, abre la vía de la necesidad de un Public compliance específico que considere sus

\footnotetext{
${ }^{162}$ La posición del ciudadano es distinta a la del socio, mientras que el primero participa en una actividad lucrativa, el segundo no lo hace. Por lo tanto, se estaría castigando a los ciudadanos que verían mermados ciertos servicios. Véase, NIETO MARTíN, "De la ética pública al Public compliance: Sobre la prevención de la corrupción en las Administraciones Públicas", cit. nota n²2, p.37.

${ }^{163}$ La multa, no obstante, reviste aristas también en el terreno de las entidades privadas, puesto que se cuestiona su idoneidad como pena obligatoria para controlar a la persona jurídica considerada como peligrosa. Sobre la cuestión con detenimiento, véase FARALDO CABANA, Patricia, "Las sanciones para personas jurídicas, con especial referencia a las sanciones pecuniarias", ponencia pronunciada en el Segundo Congreso Latinoamericano de Derecho Penal y Criminología, Argentina, 2015.

${ }^{164}$ El art. 9 bis de la LO 8/2007, introducido por la LO 3/2015, expresamente obliga a los partidos políticos a "adoptar en sus normas internas un sistema de prevención de conductas contrarias al ordenamiento jurídico y de supervisión, a los efectos previstos en el artículo 31 bis del Código Penal".

${ }^{165}$ El Consello de Contas gallego contempla en su plan de trabajo de 2017 la evaluación del diseño e implantación de los sistemas de control interno y de gestión de riesgos en las sociedades mercantiles del sector público autonómico de la Comunidad Autónoma.

${ }^{166}$ Así lo pone en evidencia y critica GÓMEZ RIVERO, "El castigo penal de la corrupción en el ámbito del llamado sector instrumental", cit. nota n 158, p. 9.

${ }^{167}$ El objetivo de la intervención sería en exclusiva la reorganización preventiva de la entidad, por lo que no afectaría a la autonomía política. Esta sanción podría ser impuesta, por ejemplo, por la autoridad central en materia de corrupción y que no fuera calificada de penal. Sobre esta propuesta, véase, NIETO MARTÍN, "De la ética pública al Public compliance: Sobre la prevención de la corrupción en las Administraciones Públicas", cit. nota nº 22, p.38.
} 
Polít. crim. Vol. 13, No 25 (Julio 2018) Art. 3, pp. 104-143.

[http://www.politicacriminal.cl/Vol_13/n_25/Vol13N25A3.pdf]

singularidades, teniendo en cuenta que ya existen casos que, aunque no se puedan perseguir a la persona jurídica por ser anteriores a la reforma, muestran que en un futuro nada lejano podrían empezar a entrar a escena las Administraciones públicas responsables penalmente ${ }^{168}$. Este nuevo escenario no debe hacernos perder de vista que el incentivo nunca podrá ser "la responsabilidad penal de la persona jurídica pública", por su propia fisonomía, sino precisamente la confianza, integridad, prestigio y buen funcionamiento de una institución pública que, a fin de cuentas, es sufragada por los ciudadanos.

168 Piénsese en el "caso Acuamed" (Sociedad estatal Aguas de las Cuencas Mediterráneas S.A.), cuyo objeto social es la contratación, construcción, adquisición y explotación de toda clase de obras hidráulicas), acusada de un presunto fraude millonario en la adjudicación de obras y calificada incluso por el juez como una auténtica organización criminal. https://politica.elpais.com/politica/2017/03/24/actualidad/1490352045_106678.html (Último acceso: 11/08/2017) 
GUTIERREZ, Elena. “Corrupción pública: concepto y mediciones. Hacia el Public compliance como herramienta de prevención de riesgos penales".

\section{Bibliografía}

BERMEJO, Mateo, "Elección racional, oportunidad para delinquir y prevención situacional: la utilidad de este enfoque para el estudio de la delincuencia empresarial", en MIRÓ LLINARES, Fernando, AGUSTINA SANLLEHÍ, José, MEDINA SARMIENTO, José Eugenio, y SUMMERS, Lucia, (coords.), Crimen, oportunidad y vida diaria: libro homenaje al profesor Dr. Marcus Felson. Madrid, 2015, pp. 305-328.

BLANCO CORDERO, Isidoro, "Hospitalidad e invitaciones a empleados públicos y privados: riesgo penal y cumplimiento normativo empresarial”, en JAREÑO LEAL, Ángeles, y DOVAL PAIS, Antonio, Corrupción pública, prueba y delito: Cuestiones de libertad e intimidad, Cizur Menor: Aranzadi, 2015, pp. 6786.

CLARKE, Ronald, "Situational crime prevention: Its theoretical basis and practical scope", Crime and Justice: An annual review of research, $\mathrm{n}^{\circ} 4$ (1983), pp. 91150.

COHEN, Lawrence, y FELSON, Marcus, "Social change and crime rate trends: A routine activity approach", en ASR, vol. 44, n4 (1979), pp. 588-608.

COX, Taylor, Cultural Diversity in Organizations - Theory, Research and practice, San Francisco: Berret-Koehler Publishers, 1993.

DOVAL PAIS, Antonio, "Delitos de corrupción pública: indultos y condenas", en: JAREÑO LEAL, Ángeles, Corrupción pública: Cuestiones de política criminal (I), Madrid: Iustel, pp. 41-62.

DE LA CUESTA ARZAMENDI, José Luis, "Responsabilidad de las personas jurídicas en el Derecho español”, en EL MISMO, Responsabilidad penal de las personas jurídicas, Cizur Menor: Aranzadi, 2013, pp. 49-102.

DEL MORAL GARCÍA, Antonio, "Justicia penal y corrupción: déficits, resultados, posibilidades", Revista Vasca de Administración Pública, nº104 (2016), pp. 4375.

DÍEZ GETINO, José Enrique, y TORIJA HERRERO, Susana, "Modelo de estrategia para fomentar la integridad y prevenir la corrupción", Revista de Transparencia e Integridad, $\mathrm{n}^{\mathrm{o}} 2$ (2016), pp.1-23.

DOPICO GÓMEZ-ALLER, Jacobo, “Aproximación a las necesidades de reforma legal en relación con la respuesta penal a la corrupción política", Cuadernos penales José María Lidón, nº11 (2015), pp. 257-284.

FELSON, Marcus, y CLARKE, Ronald: Business and Crime Prevention, Nueva York: Criminal Justice Press, 1997.

FERNÁNDEZ ASENJO, José Antonio, "El control de las Administraciones Públicas y la lucha contra la corrupción”, Cizur Menor: Civitas, 2011. 
Polít. crim. Vol. 13, № 25 (Julio 2018) Art. 3, pp. 104-143.

[http://www.politicacriminal.cl/Vol_13/n_25/Vol13N25A3.pdf]

GARZÓN VALDÉS, Ernesto, “Acerca del concepto de corrupción”, en LAPORTA SAN MIGUEL, Francisco, y ÁLVAREZ MEDINA, Silvina, La corrupción política, Madrid: Alianza Editorial, 1997, pp. 39-70.

GÓMEZ RIVERO, Carmen, "El castigo penal de la corrupción en el ámbito del llamado sector instrumental", Revista Electrónica de Ciencia Penal y Criminología, no 18 (2016), pp. 1-36.

GÓRRIZ ROYO, Elena, “Corrupción urbanística: Análisis criminológico y respuestas jurídico-penales”, en JAREÑO LEAL, Ángeles, Corrupción pública: Cuestiones de política criminal (I), Madrid, 2014, pp. 89-148.

GRAYCAR, Adam y VILLA, Diego, «The loss of governance capacity through corruption», Governance, nº 24 (2011), pp. 419-438.

JAREÑO LEAL, Ángeles, Corrupción y delincuencia de los funcionarios en la contratación pública, Madrid: Iustel, 2011.

JEREZ DARIAS, Luis, MARTÍN MARTÍN, Víctor y PÉREZ GONZÁLEZ, Ramón, "Aproximación a una geografía de la corrupción urbanística en España”, Ería, no 87 (2012), pp. 5-18.

JIMÉNEZ SÁNCHEZ, Fernando, "La trampa política: La corrupción como problema de acción colectiva", en PASTOR SELLER, Enrique, TAMEZ GONZÁLEZ, Gerardo, y SÁENZ LÓPEZ, Karla, Gobernabilidad, ciudadanía y democracia participativa: análisis comparado España-México, Madrid: 2014, Dykinson, pp. 157-174.

JIMÉNEZ SÁNCHEZ, Fernando, "Las hojas y el rábano: tres errores en el combate de la corrupción”, Claves de Razón Práctica, no 246 (2016), pp. 9-21.

KJELLBERG, Francesco, "Corfrancesuption as an analytical problem: some notes on research in Public Corruption", Indian Journal of Administrative Sciencie, $\mathrm{n}^{\circ} 3$ (1992), pp. 195-221.

KLITGAARD, Robert, Controlling Corruption, Berkeley: University of California Press, 1988.

KLITGAARD, Robert, Controlando la corrupción. Una indagación práctica para el gran problema del fin de siglo, Buenos Aires: Ed. Sudamericana, 1994.

LAPUENTE, Vicente, La corrupción en España. Un paseo por el lado oscuro de la democracia y el gobierno, Madrid: Alianza, 2016.

LUZÓN PEÑA, Alejandro, "Instrumentos para la investigación de la corrupción", Cuadernos penales José María Lizón, n 11 (2015), pp. 235-254. 
GUTIERREZ, Elena. “Corrupción pública: concepto y mediciones. Hacia el Public compliance como herramienta de prevención de riesgos penales".

QUERALT JIMÉNEZ, Joan Josep, «Public Compliance y corrupción: Análisis conceptual y propuestas», Revista Internacional Transparencia e Integridad, $\mathrm{n}^{\circ} 2$ (2016), pp. 1-11.

QUERALT JIMÉNEZ, Joan Josep, “Diez acciones inmediatas contra la corrupción”, en CASTRO MORENO, Abraham, y OTERO GONZÁLEZ, Pilar, Prevención y tratamiento punitivo de la corrupción en la contratación pública y privada, Madrid: Dykinson, 2016, pp. 95-100.

MEDINA ARNÁIZ, Teresa, "La necesidad de reformar la legislación sobre contratación pública para luchar contra la corrupción: las obligaciones que nos llegan desde Europa", Revista Vasca de Administración Pública, nº104 (2016), pp. $77-113$.

NIETO GARCÍA, Alejandro, El desgobierno de lo público, Barcelona: Ariel, 2008.

NIETO GARCÍA, Alejandro, Corrupción en la España democrática, Barcelona: Ariel, 1997.

NIETO MARTÍN, Adán, "De la ética pública al public compliance: sobre la prevención de la corrupción en las administraciones públicas", en EL MISMO y MAROTO CALATAYUD, Manuel, (Dirs.), Public Compliance. Prevención de la corrupción en administraciones públicas y partidos políticos, Cuenca: Ediciones Universidad Castilla La Mancha, 2014, pp. 17-42.

ONRUBIA FERNÁNDEZ, Jorge, "La lucha contra la corrupción en el sector público: fiscalización, intervención y control económico-financiero", Public Compliance. Prevención de la corrupción en administraciones públicas y partidos políticos, Cuenca: Ediciones Universidad Castilla La Mancha, 2014, pp. 221-250.

PATERNOSTER, Raymond, y SIMPSON, Sally, "A rational choice theory of corporate crime», en CLARKE, Ronald, y FELSON, M., Routine Activity and rational choice. Advances in criminological theory, Londres: Transaction Publishers, 1993.

PEÑA OCHOA, Alfonso, "El nuevo rol de los organismos de control externo frente a la corrupción”, en NIETO MARTÍN, Adán, y MAROTO CALATAYUD, Manuel, (Dirs.), Public Compliance. Prevención de la corrupción en administraciones públicas y partidos políticos, Cuenca: Ediciones Universidad Castilla La Mancha, 2014, pp. 83-108.

PERSON, Anna, ROTHSTEIN, Bo, y TEORELL, Jan, "Why anticorruption reforms fail. Systemic corruption as a collective action problem", en Governance, no 26 (2013), pp. 449-471.

PONCE SOLÉ, Juli, "La prevención de la corrupción mediante la garantía del derecho a un buen gobierno y a una buena administración en el ámbito local (con referencias al Proyecto de Ley de transparencia, acceso a la información pública y buen gobierno)", en Anuario del Gobierno Local, n¹ (2012), pp. 93-140. 
Polít. crim. Vol. 13, № 25 (Julio 2018) Art. 3, pp. 104-143.

[http://www.politicacriminal.cl/Vol_13/n_25/Vol13N25A3.pdf]

RODRÍGUEZ FERRÁNDEZ, Samuel, "La ¿evaluación? de las normas penales en España”, en $R E C P C, \mathrm{n}^{\circ} 15$ (2013), pp. 1-43.

SEBASTIÁN GASCÓN, Carlos, España estancada. Por qué somos poco eficientes, Barcelona: Galaxia Gutenberg, 2016.

TARÍN, Carolina, "La medición de la corrupción en España: Los datos objetivos", en VILLORIA MENDIETA, Manuel, GIMENO FELIÚ, José María, y TEJEDOR BIELSA, Julio, La corrupción en España. Ámbitos, causas y remedios jurídicos, Barcelona: Atelier, 2016, pp. 67-82.

VILLORIA MENDIETA, Manuel e IZQUIERDO SÁNCHEZ, Agustín, Ética pública y buen gobierno. Regenerando la democracia y luchando contra la corrupción desde el servicio público, Madrid: Tecnos, 2016.

VILLORIA MENDIETA, Manuel, y JIMÉNEZ SÁNCHEZ, Fernando, “¿Cuánta corrupción hay en España? Los problemas metodológicos de la medición de la corrupción (2004-2011)”, en Revista de Estudios Políticos, nº156 (2012), pp. 1347.

VILLORIA MENDIETA, Manuel, "El buen gobierno y la lucha contra la corrupción en las instituciones públicas", en PALOMAR OLMEDA, Alberto y GARCÉS SANAGUSTÍN, La gestión de los fondos públicos: control y responsabilidades: Los derechos de los ciudadanos, las garantías y las vías de actuación para su efectividad, Cizur Menor: Aranzadi, 2013, pp. 123-156. 